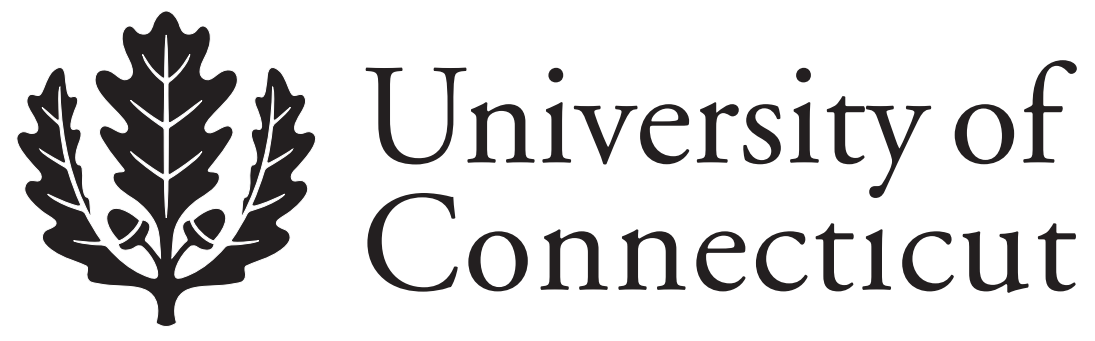

Department of Economics Working Paper Series

\title{
Auctions with a Buy Price: The Case of Reference-Dependent Preferences
}

Nicholas Shunda

University of Connecticut

Working Paper 2007-42

October 2007

341 Mansfield Road, Unit 1063

Storrs, CT 06269-1063

Phone: (860) 486-3022

Fax: (860) 486-4463

http://www.econ.uconn.edu/

This working paper is indexed on RePEc, http://repec.org/ 


\begin{abstract}
In an auction with a buy price, the seller provides bidders with an option to end the auction early by accepting a transaction at a posted price. The "BuyIt-Now" option on eBay is a leading example of an auction with a buy price. This paper develops a model of an auction with a buy price in which bidders use the auction's reserve price and buy price to formulate a reference price. The model both explains why a revenue-maximizing seller would want to augment her auction with a buy price and demonstrates that the seller sets a higher reserve price when she can affect the bidders' reference price through the auction's reserve price and buy price than when she can affect the bidders' reference price through the auction's reserve price only. Introducing a small reference-price effect can shrink the range of buy prices bidders are willing to exercise. The comparative statics properties of bidding behavior are in sharp contrast to equilibrium behavior in other models where the existence and size of the auction's buy price have no effect on bidding behavior.
\end{abstract}

Journal of Economic Literature Classification: D44, D82, L86

Keywords: Auction, Buy price, Internet, Reference-dependence?

I would like to thank Vicki Knoblauch for her insightful comments on earlier versions of this paper. 


\section{Introduction}

The proliferation of auctions on the internet brought with it the emergence of a hybrid market institution in which an auction and a posted price coexist, an auction with a buy price. In auctions with a buy price (such prices are called "Buy-It-Now" on eBay, "Buy Price" on Yahoo!, and "Take-It" on Amazon), the seller provides bidders with an option to end the auction early by accepting a transaction at the posted price. Bidders, of course, can reject the buy price in favor of participating in the auction. The buy price at eBay, the industry leader in online auctions, is a "temporary" buy price in that it disappears once a bidder places a bid on the item for sale. Other buy prices, such as the ones present on Yahoo! and Amazon, are "permanent" buy prices in that they are available to bidders through the auction's entire duration and thus place an upper bound on the seller's revenue.

Despite the relative novelty of this market institution, auctions with a buy price are economically significant and popular among buyers and sellers in online auctions. The recent sales figures from eBay in Table 1 make clear the economic importance of auctions with a buy price. ${ }^{1}$ Recent quarterly sales at eBay range between $\$ 10.6$ and $\$ 14.4$ billion, and buy price transactions account for a share of between $32 \%$ and $41 \%$ of these quarterly sales. Sellers choose to augment their auction with a buy price in between $30 \%$ and $60 \%$ of online auctions depending upon the product category, and, among those auctions with a buy price, between $10 \%$ and $40 \%$ end with a transaction at the buy price; see, for example, the figures cited by Hof (2001), Kane (2002), Durham et al. (2004), Wang et al. (2004), Mathews and Katzman (2006), Anderson et al. (2007a, 2007b), Popkowski Leszczyc et al. (2007), and Reynolds and Wooders (2007). At first glance, the popularity of augmenting auctions with a buy price appears to be something of a puzzle given that sellers typically prefer auctions over posted prices for selling goods when the market price is uncertain (Milgrom, 1989; Wang, 1993).

To address this puzzle, we develop and study a model of an auction with a temporary buy price where bidders use the auction's reserve price and buy price to formulate a reference price. In the standard analysis of auctions, bidders evaluate alternatives on the basis of the difference between their valuation and their payment. In contrast, bidders with referencedependent preferences assess alternatives in relation to some fixed standard, a reference point (Kahneman \& Tversky, 1979; Tversky \& Kahneman, 1991; Köszegi \& Rabin, 2006; Rosenkrantz \& Schmitz, 2007). Thus, when bidders have reference-dependent preferences, the auction's reserve price and buy price can serve as signals of value to bidders. Further, when an auction's buy price signals value to bidders, sellers might be willing to augment their auctions with buy prices even if bidders are unlikely to exercise the option. Numerous

\footnotetext{
${ }^{1}$ The data in Table 1 are available online at http://investor.ebay.com/index.cfm.
} 
Table 1: eBay Quarterly Sales Data for 2005Q1-2007Q3

\begin{tabular}{ccc}
\hline \hline Quarter & Gross Merchandise Volume & Fixed-Price Share \\
\hline 2005Q1 & $\$ 10.6$ billion & $\mathrm{N} / \mathrm{A}$ \\
2005Q2 & $\$ 10.8$ billion & $\mathrm{N} / \mathrm{A}$ \\
2005Q3 & $\$ 10.8$ billion & $32 \%$ \\
2005Q4 & $\$ 12.0$ billion & $34 \%$ \\
2006Q1 & $\$ 12.5$ billion & $34 \%$ \\
2006Q2 & $\$ 12.8$ billion & $35 \%$ \\
$2006 Q 3$ & $\$ 12.6$ billion & $37 \%$ \\
$2006 Q 4$ & $\$ 14.4$ billion & $38 \%$ \\
$2007 Q 1$ & $\$ 14.2$ billion & $39 \%$ \\
$2007 Q 2$ & $\$ 14.4$ billion & $39 \%$ \\
$2007 Q 3$ & $\$ 14.3$ billion & $41 \%$ \\
\hline
\end{tabular}

studies establish that consumers utilize reference prices to guide their purchasing behavior in mundane transactions; for reviews of this literature, see Kalyanaram and Winer (1995) and Mazumdar et al. (2005). With the rapid growth in auctions on the internet, it is likely that bidder decision making also features reference-dependence. Recent results of laboratory and field experiments by Ariely and Simonson (2003), Häubl and Popkowski Leszczyc (2003), Kamins et al. (2004), and Suter and Hardesty (2005) indicate that bidders utilize auctions' reserve prices to formulate their reference price and the results of studies by Dodonova and Khoroshilov (2004) and Popkowski Leszczyc et al. (2007) indicate that bidders use auctions' buy prices to formulate their reference price. Thus, studying a model of bidders with reference-dependent preferences in auction with a buy price seems warranted and is one way in which we can gain insight into bidder and seller behavior in this market institution.

We model an auction with a buy price as a two-stage game and ask the following questions: 1. How do bidders behave regarding accepting or rejecting a transaction at the buy price in the first stage? 2. How do bidders with reference-dependent preferences bid in the second stage auction? 3. How should a revenue-maximizing seller set her auction's buy price and reserve price when she anticipates bidders' equilibrium behavior? We establish the existence and uniqueness of equilibrium in our model of an auction with a buy price, and find that bidders' use of the auction's buy price in formulating their reference price provides a rationale for why a revenue-maximizing seller would want to augment her auction with a buy price. We also note how bidders' equilibrium behavior differs from behavior in the standard model where bidders have reference-free preferences. In particular, we describe situations in which introducing a small reference-price effect can shrink the range of buy prices bidders are willing to exercise in equilibrium, and we establish comparative statics properties of 
equilibrium bidding behavior that illustrates a sharp contrast between our model and other models of auctions with a buy price where the existence and size of the auction's buy price have no effect on bidders' behavior in the second stage auction (Mathews \& Katzman, 2006; Seifert, 2006; Ivanova-Stenzel \& Kröger, 2007; Reynolds \& Wooders, 2007).

There is a growing theoretical literature that seeks to understand under what conditions a revenue-maximizing seller would benefit from augmenting her auction with a buy price. Models in this literature feature either English ascending or second-price sealed-bid auctions, and all fall within the symmetric independent private values framework in which bidders' valuations are private information and are drawn from some common distribution. Emerging from this literature are four rationales for augmenting an auction with a buy price: 1. Bidder or seller risk-aversion; 2. Bidder or seller impatience; 3. Bidder transaction costs; and 4. Seller competition and bidders with multi-unit demands.

Budish and Takeyama (2001) study a two-bidder, two-type model, and find that a risk-neutral seller stands to gain by augmenting her auction with a (permanent) buy price when bidders are risk-averse. The buy price option acts as a form of insurance for risk-averse bidders, and thus they are willing to pay a premium for an auction with such an option. Hidvégi et al. (2006) generalize these results to a model with $n$ bidders and a continuum of types, and Seifert (2006) and Ivanova-Stenzel and Kröger (2007) generalize the model for the case of a temporary buy price and obtain similar results. Reynolds and Wooders (2007) compare the performance of auctions with permanent and temporary buy prices for riskneutral sellers facing risk-averse sellers and outline the conditions under which the two types of auctions with a buy price are revenue-equivalent and under which bidders prefer one type of auction over the other. Mathews (2003) and Mathews and Katzman (2006) investigate a risk-averse seller facing risk-neutral bidders in an auction with a temporary buy price and find that such a seller can gain from augmenting her auction with a buy price. Again, the buy price option acts as a form of insurance for risk-averse sellers by lowering the variability of their expected revenue.

While bidder or seller risk-aversion are to date the most frequently studied rationales for auctions with a buy price, the literature offers a number of complementary explanations for this hybrid market institution. Mathews (2004) studies a continuous time auction with a temporary buy price in which either the seller or the bidders are impatient and finds that a patient seller facing impatient bidders can improve her expected revenue by augmenting her auction with a buy price. An impatient seller facing patient bidders can improve her discounted expected revenue in a similar fashion. Wang et al. (2004) find that if bidders face transaction costs from participating in the auction, a seller can gain from adding a temporary 
buy price to her auction. Bidders are willing to pay a premium for such an option since it enables them to enact a transaction upon arriving at the auction and thus to avoid costly participation in the auction. Kirkegaard and Overgaard (2007) study a two-seller model in which the sellers compete in sequence and bidders have two-unit demands and find that the first seller can improve her expected revenue by offering a temporary buy price. In a model with a a set of types that is not connected, Bose and Daripa (2006) find that a second-price sealed-bid auction with a temporary buy price implements the seller's optimal selling mechanism. Such a hybrid mechanism is optimal for the seller because it enables her to segment her market and price discriminate among the relatively higher and highest valuation bidders in a way in which she cannot with either a pure auction or posted price selling.

Two features of the theoretical literature on auctions with a buy price deserve further comment. First, in the absence of discounting, transaction costs, or competing sellers and multi-unit demands, a result recurring in the literature is that a risk-neutral seller facing risk-neutral bidders cannot improve her expected revenue by augmenting her auction with a buy price (Budish \& Takeyama, 2001; Hidvégi et al., 2006; Mathews \& Katzman, 2006; Seifert, 2006; Ivanova-Stenzel \& Kröger, 2007; Reynolds \& Wooders, 2007). Second, without exception, the existence or size of a temporary buy price does not affect the bidders' behavior in the auction (Mathews, 2003, 2004; Wang et al., 2004; Mathews \& Katzman, 2006; Seifert, 2006; Ivanova-Stenzel \& Kröger, 2007; Reynolds \& Wooders, 2007). That is, bidders will bid according to their dominant strategy should they reject the buy price option and reach the auction irrespective of the existence or magnitude of the auction's buy price (or reserve price).

The model we develop and study in this paper contrasts with this literature in at least two respects. First, bidders and the seller are risk-neutral, and bidders' use of the buy price in formulating their reference price provides the seller with a rationale for augmenting her auction with a buy price. Second, because bidders use both the auction's reserve price and buy price to formulate their reference price, changes in these auction prices affect bidding behavior in a predictable way. The comparative statics properties of bidding behavior our model generates accords well with evidence from the laboratory and from the field that bidding behavior in second-price sealed-bid (and open English) auctions is consistent with bidders having reference-dependent preferences with a reference price that depends upon either the auction's reserve price, its buy price, or both prices. The results of studies by Ariely and Simonson (2003), Häubl and Popkowski Leszczyc (2003), Kamins et al. (2004), and Suter and Hardesty (2005) indicate that bidders use auctions' reserve prices to formu- 
late their reference price and bid more aggressively in auctions with higher reserve prices. Dodonova and Khoroshilov (2004) and Popkowski Leszczyc et al. (2007) find that auctions with higher buy prices cause bidders to bid more aggressively and have higher closing prices even when the bidders do not exercise the auction's buy price option. List and Shogren (1999), Nunes and Boatwright (2004), Bernard (2005), Dholakia and Simonson (2005), Corrigan and Rousu (2006), and Drichoutis et al. (2007) find evidence that bidders use other posted prices (e.g., closing prices of earlier or adjacent auctions) to formulate their reference price. Thus, this paper contributes to the literature by identifying an additional rationale for a seller to augment her auction with a buy price and produces bidding behavior that is consistent with behavior observed in the laboratory and the field but that other models of auctions with a buy price cannot explain.

The remainder of the paper is organized as follows. Section 2 contains our model of an auction with a buy price as well as an analysis of bidders' equilibrium behavior regarding acceptance of the buy price and bidding in the auction. Section 3 contains an analysis of how a risk-neutral seller would design her auction. Section 4 contains concluding remarks.

\section{An Auction with a Buy Price}

In an auction with a buy price, a seller offers bidders the opportunity to end the auction early by accepting a posted price offer. Throughout this paper, we will refer to such an offer as a buy price, though it goes by different names depending upon the auction in which it appears. ${ }^{2}$ Buy prices in auctions differ in their duration, with "temporary" buy prices only existing as long as no bidder has yet placed a bid (as on the site of industry leader, eBay) and with "permanent" buy prices lasting the entire duration of the auction (as on the sites of Yahoo! and Amazon). In this paper, we study an auction with a temporary buy price.

Consider an auction with a buy price with $n \geq 2$ bidders where a seller offers a one unit of an indivisible good at a buy price $B^{*}$ and, if no bidder accepts the buy price, holds a second-price sealed-bid auction. ${ }^{3}$ The auction's minimum acceptable bid is a reserve price $r$ set by the seller. We require that $B^{*} \geq r$ so that the seller either sells her item by posting a price $\left(B^{*}=r\right)$ or by augmenting her auction with a buy price $\left(B^{*}>r\right)$.

\footnotetext{
${ }^{2}$ Examples of buy prices in auctions are the "Buy-It-Now" price on eBay, the "Buy Price" on Yahoo!, and the "Take-It" price on Amazon.

${ }^{3}$ Auctions with buy prices are typically open English auctions, but second-price sealed-bid auctions are strategically equivalent to open English auctions. Further, because of the prevalence of late bidding and the use of proxy bidding, where a bidder enters a secret maximum bid and a computer bids just enough to win as long as the bidder's maximum bid exceeds her rivals' proxy bids, these open English auctions further resemble second-price sealed-bid auctions.
} 
The model that we study is within the symmetric independent private values framework: bidders' valuations $v_{i}$ are independent draws from the common distribution $F$ that is continuous on its support $[\underline{v}, \bar{v}]$ with $\bar{v}>\underline{v} \geq 0$ and a density $f$ that is finite on its support and bounded away from zero. The number of bidders, the seller's buy price and reserve price, and the distribution of values are common knowledge, though each bidder's own valuation is private information.

The formulation of the bidders' preferences is a novel feature of the analysis. In particular, we assume that bidders have reference-dependent preferences (Kahneman \& Tversky, 1979; Tversky \& Kahneman, 1991; Köszegi \& Rabin, 2006; Rosenkrantz \& Schmitz, 2007). In the standard analysis of auctions, bidders evaluate alternatives on the basis of the difference between their valuation and their payment. In contrast, bidders with reference-dependent preferences assess alternatives in relation to some fixed standard, a reference point. In particular, we assume that bidders use the auction's reserve price and its buy price in formulating their reference price. If bidder $i$ wins the item and pays $x$, her payoff is

$$
v_{i}-x-\varepsilon(x-\rho)
$$

and is zero otherwise. The reference price is $\rho$ and $\varepsilon$ is a small positive number. The standard reference-free preferences in auction theory have $\varepsilon=0$. To preserve ex ante symmetry, we assume that all bidders have the same reference price

$$
\rho=\lambda r+(1-\lambda) B^{*}
$$

with $\lambda \in(0,1)$. Thus, each bidder's reference price is a convex combination of the auction's reserve price and its buy price. ${ }^{4}$

An auction with a buy price is a two-stage game. In the first stage, bidders simultaneously and noncooperatively decide whether or not to accept the buy price. If at least one bidder accepts the buy price, the game ends and the seller completes a transaction with the successful bidder at the buy price; the seller breaks ties at random if more than one bidder accepts the buy price. If no bidder accepts the buy price, they move to the second stage where they compete for the good by submitting bids to a second-price sealed-bid auction. Since the buy price is temporary, a bidder's decision to reject it is irreversible.

\footnotetext{
${ }^{4}$ Rosenkrantz and Schmitz (2007) introduced reference-dependent preferences into auction theory in their study of bidder behavior and a seller's design of first- and second-price sealed-bid auctions. They assume that bidders formulate their reference price as a convex combination of the auction's reserve price and some exogenous price $x$; that is, the bidders' reference price is $\rho=\lambda r+(1-\lambda) x$. Our model follows the Rosenkrantz and Schmitz (2007) formulation closely, but we replace $x$ with $B^{*}$, the auction's buy price.
} 
A bidder's strategy consists of a rule of whether or not to exercise the buy price and a bid in the auction. Since a bidder's decision regarding the buy price depends upon her expectations regarding the auction, we solve the model by backward induction and analyze the auction in the second stage first.

\subsection{Stage Two: A Second-Price Sealed-Bid Auction}

If no bidder accepts the buy price $B^{*}$ in the first stage, they then compete for the item by submitting bids to a second-price sealed-bid auction with a reserve price $r$. If bidder $i$ wins the auction, she receives a payoff of

$$
v_{i}-\max _{j \neq i}\left\{b_{j}\right\}-\varepsilon\left(\max _{j \neq i}\left\{b_{j}\right\}-\rho\right),
$$

and zero otherwise. That is, a winning bidder has the highest bid but pays the amount of the second-highest bid tendered in the auction.

A symmetric equilibrium features bidders using the same bid function $\beta\left(v_{i}\right)$ in the auction. As in the standard second-price sealed-bid auction with reference-free preferences, bidders have a dominant bidding strategy. All proofs appear in the paper's Appendix.

Proposition 1. In the second-price sealed-bid auction, a bidder of type $v_{i}$ has a weakly dominant strategy to bid

$$
\beta\left(v_{i}\right)=\frac{v_{i}+\varepsilon \rho}{1+\varepsilon}
$$

if $v_{i} \geq \underline{\underline{v}}=(1+\varepsilon) r-\varepsilon \rho$, and to not participate in the auction otherwise.

Note that the bidding behavior in Proposition 1 differs from the well-known result that bidders have a weakly dominant strategy to reveal their valuation truthfully in their bids in a second-price sealed-bid auction (Vickrey, 1961). Bids differ from valuations in this model due to bidders' reference-dependent preferences; clearly, if $\varepsilon=0$, we would have the standard result of $\beta\left(v_{i}\right)=v_{i}$ in equation (1). Nonetheless, the equilibrium bidding behavior in Proposition 1 has an intuitive interpretation. In a second-price sealed-bid auction, a bidder bids up until the point where she would receive a payoff of zero if she had to pay her bid, a payment that occurs only in the event of ties, an event with probability zero in

equilibrium. Bidding in this way maximizes the probability of winning without risking a negative payoff in the event where a bidder would have to pay her bid.

Note that the critical valuation $\underline{\underline{v}}=(1+\varepsilon) r-\varepsilon \rho$ for participating in the auction is a 
function of both the auction's buy price and its reserve price. ${ }^{5}$ Note also that

$$
\frac{\partial \underline{\underline{v}}}{\partial B^{*}}=-\varepsilon(1-\lambda)<0
$$

and

$$
\frac{\partial \underline{\underline{v}}}{\partial r}=1+\varepsilon-\varepsilon \lambda>0 .
$$

That is, all else equal, a higher buy price has the effect of encouraging bidders to forgo purchasing the item at the buy price and to participate in the auction, while a higher reserve price has the effect of discouraging relatively low valuation bidders from participating in the auction. For ease of notation in the analysis that follows, we omit the functional relationship between $\underline{\underline{v}}$ and $B^{*}$ and $r$ except when doing so would cause unnecessary confusion.

A few features of the equilibrium bid function in equation (1) deserve mention. First, note that $\beta\left(v_{i}\right) \gtrless v_{i}$ if $\rho \gtrless v_{i}$, and so we could observe underbidding relative to the standard model with reference-free preferences $(\varepsilon=0)$ if a bidder's reference price is less than her valuation. Alternatively, we could observe bids that exceed valuations if a bidder's reference price exceeds her valuation; in such cases, the auction's buy price must form part of the bidders' reference price, that is, we must have $\lambda \neq 1$. Second, $\beta\left(v_{i}\right)$ is increasing in both $B^{*}$ and $r$. If bidders use the auction's buy price and reserve price to formulate their reference price, increases in these prices cause bidders to bid more aggressively in the auction. That is, if $\varepsilon>0$ and $\lambda \in(0,1)$,

$$
\frac{\partial \beta\left(v_{i}\right)}{\partial B^{*}}=\frac{\varepsilon(1-\lambda)}{1+\varepsilon}>0
$$

and

$$
\frac{\partial \beta\left(v_{i}\right)}{\partial r}=\frac{\varepsilon \lambda}{1+\varepsilon}>0 .
$$

If $\varepsilon=0$, bidders' preferences are reference-free and their bids are independent of the auction's buy price and reserve price. If $\varepsilon>0$ and $\lambda=0$, bidders use only the auction's buy price to formulate their reference price, and their bids are independent of the auction's reserve price but are increasing in the auction's buy price. If $\varepsilon>0$ and $\lambda=1$, bidders use only the auction's reserve price to formulate their reference price, and their bids are independent of the auction's buy price but are increasing in the auction's reserve price. Finally, if bidders use the auction's buy price and reserve price to formulate their reference price, the strength of the reference-price effect moderates the effects of the buy price and reserve price on bids.

\footnotetext{
${ }^{5}$ Since $B^{*} \geq r$, a bidder that is indifferent between participating in the auction and not is indifferent between participating in the auction and purchasing the item at the buy price if $B^{*}=r$ and strictly prefers participating in the auction to purchasing the item at the buy price if $B^{*}>r$.
} 
That is, if $\varepsilon>0$ and $\lambda \in(0,1)$,

$$
\frac{\partial^{2} \beta\left(v_{i}\right)}{\partial \varepsilon \partial B^{*}}=\frac{\varepsilon(1-\lambda)}{(1+\varepsilon)^{2}}>0
$$

and

$$
\frac{\partial^{2} \beta\left(v_{i}\right)}{\partial \varepsilon \partial r}=\frac{\varepsilon \lambda}{(1+\varepsilon)^{2}}>0
$$

The weight bidders place on the auction's reserve price in formulating their reference price also has a moderating role since

$$
\frac{\partial^{2} \beta\left(v_{i}\right)}{\partial \lambda \partial B^{*}}=\frac{-\varepsilon}{1+\varepsilon}<0
$$

and

$$
\frac{\partial^{2} \beta\left(v_{i}\right)}{\partial \lambda \partial r}=\frac{\varepsilon}{1+\varepsilon}>0
$$

We record these properties in the following corollary.

Corollary 1. If $\varepsilon>0$ and $\lambda \in(0,1)$, the equilibrium bid function in equation (1) is increasing in both the auction's buy price and its reserve price. The strength of the reference-price effect and the weight bidders place on the auction's reserve price in formulating their reference price moderate the effects of the buy price and reserve price on bids.

This result is in sharp contrast to existing models of auctions with buy prices in which the existence of a temporary buy price does not affect bidding behavior in the auction; see, for example, Mathews (2002, 2003, 2004), Wang et al. (2004), Mathews and Katzman (2006), Seifert (2006), Ivanova-Stenzel and Kröger (2007), and Reynolds and Wooders (2007). Thus, the content of Corollary 1 provides the basis for an empirical test of our model of bidders with reference-dependent preferences in an auction with a buy price and differentiates it from existing models of auctions with buy prices.

Further, the content of Corollary 1 accords well with evidence from the laboratory and from the field that bidding behavior in second-price sealed-bid (and open English) auctions is consistent with bidders having reference-dependent preferences with a reference price that depends upon either the auction's reserve price, its buy price, or both prices. The results of studies by Ariely and Simonson (2003), Häubl and Popkowski Leszczyc (2003), Kamins et al. (2004), and Suter and Hardesty (2005) indicate that bidders use auctions' reserve prices to formulate their reference price and bid more aggressively in auctions with higher reserve prices. Dodonova and Khoroshilov (2004) and Popkowski Leszczyc et al. (2007) find that auctions with higher buy prices cause bidders to bid more aggressively and lead to higher 
closing prices even when the bidders do not exercise the buy price option. Thus, as Corollary 1 indicates, our model produces bidding behavior that is consistent with behavior observed in the laboratory and the field but that other models of auctions with a buy price cannot explain.

\subsection{Stage One: The Buy Price}

In the first stage, bidders observe the buy price $B^{*} \geq r$ set by the seller. Each bidder must decide whether or not to exercise the buy price option knowing how she will bid if she proceeds to the auction in the second stage. When making their decision, bidders compare the expected payoff from transacting at the buy price with the expected payoff from competing in the second stage auction.

In analyzing bidders' first stage decisions regarding the buy price, we are searching for the existence of a symmetric equilibrium of the following form: (i) each bidder accepts the buy price if and only if her valuation exceeds some critical valuation $v^{*}$ and rejects it otherwise and (ii) submits a bid of $\beta\left(v_{i}\right)=\frac{v_{i}+\varepsilon \rho}{1+\varepsilon}$ in the auction in the second stage. For the critical valuation $v^{*}$ to form part of each bidder's equilibrium strategy, we need each bidder to use $v^{*}$ to evaluate the buy price given her rivals' use of $v^{*}$, and we need bidder $i$ 's expected payoff from exercising the buy price option to exceed her expected payoff from competing in the auction if $v_{i}>v^{*}$ and the reverse if $v_{i}<v^{*}$.

For a bidder with $v_{i} \geq \underline{\underline{v}}$, the expected payoff from exercising the buy price option given that her rivals use the same critical valuation $v^{*}$ to evaluate the buy price is

$$
\begin{aligned}
\pi^{B}\left(v_{i}, v^{*}\right) & =\sum_{k=0}^{n-1}\left(\begin{array}{c}
n-1 \\
k
\end{array}\right) F\left(v^{*}\right)^{n-k-1}\left(1-F\left(v^{*}\right)\right)^{k} \frac{1}{1+k}\left(v_{i}-B^{*}-\varepsilon\left(B^{*}-\rho\right)\right) \\
& =\left(\frac{1-F\left(v^{*}\right)^{n}}{n\left(1-F\left(v^{*}\right)\right)}\right)\left(v_{i}-B^{*}-\varepsilon\left(B^{*}-\rho\right)\right)
\end{aligned}
$$

(where the second line of the equation follows from applying Newton's Binomial Formula). In her expected payoff from exercising the buy price, $k$ is the number of rival bidders that bidder $i$ expects to have valuations greater than $v^{*}$ and, thus, to exercise the buy price simultaneously. In our calculation of the expected payoff from exercising the buy price option, we account for the fact that the seller breaks ties at random if more than one bidder opts to transact at the buy price. Examining equation (2) reveals that only a bidder of type $v_{i} \geq \tilde{v}=B^{*}+\varepsilon \lambda\left(B^{*}-r\right) \geq B^{*}$ would ever consider exercising the buy price option because a bidder of type $v_{i}<\tilde{v}$ would earn receive a negative payoff from exercising the option. Further, note that $\tilde{v} \geq \underline{\underline{v}}$, and thus there could exist bidders who find participating in the 
auction worthwhile but who would not exercise the auction's buy price.

On the other hand, for a bidder with $v_{i} \geq \underline{\underline{v}}$, the expected payoff from forgoing the buy price option and bidding in the auction is

$$
\begin{aligned}
\pi^{A}\left(v_{i}, v^{*}\right)= & \left(v_{i}-r-\varepsilon(r-\rho)\right) F(\underline{\underline{v}})^{n-1} \\
& +\int_{\underline{\underline{v}}}^{\min \left\{v_{i}, v^{*}\right\}}\left(v_{i}-\frac{x+\varepsilon \rho}{1+\varepsilon}-\varepsilon\left(\frac{x+\varepsilon \rho}{1+\varepsilon}-\rho\right)\right)(n-1) F(x)^{n-2} f(x) d x \\
= & \left(v_{i}-r-\varepsilon(r-\rho)\right) F(\underline{\underline{v}})^{n-1}+\int_{\underline{\underline{v}}}^{\min \left\{v_{i}, v^{*}\right\}}\left(v_{i}-x\right)(n-1) F(x)^{n-2} f(x) d x \\
= & \left(v_{i}-\min \left\{v_{i}, v^{*}\right\}\right) F\left(\min \left\{v_{i}, v^{*}\right\}\right)^{n-1}+\int_{\underline{\underline{v}}}^{\min \left\{v_{i}, v^{*}\right\}} F(x)^{n-1} d x
\end{aligned}
$$

(where the final equality follows from integration by parts). The valuation of bidder $i$ 's strongest rival is $x$ and, since the bidders' valuations are independent draws from $F, x$ has distribution $F(x)^{n-1}$ and density $(n-1) F(x)^{n-2} f(x)$. When bidder $i$ opts to compete in the auction, all of her rivals might have valuations below $\underline{\underline{v}}$ and so she might pay the reserve price with probability $F(\underline{\underline{v}})^{n-1}$. If bidder $i$ has to compete against a rival with a valuation exceeding $\underline{\underline{v}}$, she expects to pay the bid of her strongest rival, $\beta(x)=\frac{x+\varepsilon \rho}{1+\varepsilon}$. Bidder $i$, of course, formulates her expectations conditional on the event of winning, and this is costless to her as she pays nothing if she is a losing bidder.

Following Mathews and Katzman (2006), define as $B\left(v_{i}, r\right)$ the buy price that makes a bidder of type $v_{i}$ indifferent between exercising the buy price option in the first stage and competing in the auction in the second stage. This threshold buy price $B\left(v_{i}, r\right)$ solves

$$
\int_{\underline{\underline{v}}\left(B\left(v_{i}, r\right)\right)}^{v_{i}} F(x)^{n-1} d x=\left(\frac{1-F\left(v_{i}\right)^{n}}{n\left(1-F\left(v_{i}\right)\right)}\right)\left(v_{i}-B\left(v_{i}, r\right)-\varepsilon\left(B\left(v_{i}, r\right)-\rho\right)\right) .
$$

Equation (4) expresses the equality of expected auction payoffs and expected payoffs from exercising the buy price option for a bidder of type $v_{i}$, and thus defines this bidder's indifference between participating in the second-price sealed-bid auction with reserve $r$ in the second stage and forgoing the auction by exercising the buy price option of $B\left(v_{i}, r\right)$ in the first stage. When we rearrange terms in equation (4), the equation

$$
B\left(v_{i}, r\right)=\frac{v_{i}+\varepsilon \lambda r}{1+\varepsilon \lambda}-\left(\frac{n\left(1-F\left(v_{i}\right)\right)}{\left(1-F\left(v_{i}\right)^{n}\right)(1+\varepsilon \lambda)}\right) \int_{\underline{\underline{v}}\left(B\left(v_{i}, r\right)\right)}^{v_{i}} F(x)^{n-1} d x
$$


defines $B\left(v_{i}, r\right)$ implicitly. ${ }^{6}$ In Lemma 1 in the Appendix, we demonstrate that $B\left(v_{i}, r\right)$ is increasing in $v_{i}$ and in $r$. Define as the critical valuation $v^{*}$ the unique $v \in[\underline{v}, \bar{v}]$ such that $B\left(v^{*}, r\right)=B^{*}$ and define $v^{*}=\bar{v}$ if $B(v, r)<B^{*}$ for all $v \in[\underline{v}, \bar{v}]$.

Proposition 2. There exists a symmetric equilibrium in which a bidder of type $v_{i}$ accepts the buy price if and only if

$$
B^{*}<B\left(v_{i}, r\right)
$$

and submits a bid of

$$
\beta\left(v_{i}\right)=\frac{v_{i}+\varepsilon \rho}{1+\varepsilon}
$$

in the auction. This is the unique symmetric equilibrium.

We can demonstrate the existence of a symmetric equilibrium by using an intermediate value argument, and the uniqueness of the symmetric equilibrium follows from the fact that $B\left(v_{i}, r\right)$ is increasing in $v_{i}$.

A few important features of $B\left(v_{i}, r\right)$ become apparent when we examine equation (5), the equation that defines $B\left(v_{i}, r\right)$ implicitly. First, $B(\underline{v}, r)=r$. We can interpret this in one of two ways. A buy price of $r$ makes a bidder of type $\underline{\underline{v}}$ indifferent between exercising the buy price option and participating in the auction (with reserve price $r$ ) in equilibrium. Equivalently, if a seller sets a buy price of $r$, all bidders with valuations exceeding $\underline{\underline{v}}$ will exercise the buy price option in equilibrium. Second, $B(\bar{v}, r)=\lim _{v_{i} \rightarrow \bar{v}} B\left(v_{i}, r\right)$ is the buy price that makes a bidder of type $\bar{v}$ indifferent between exercising the buy price option and participating in the auction in equilibrium. If a seller sets a buy price $B^{*}>B(\bar{v}, r)$, no bidder will opt for the buy price in equilibrium, and all bidders will instead choose to participate in the auction. The equation

$$
B(\bar{v}, r)=\frac{\bar{v}+\varepsilon \lambda r}{1+\varepsilon \lambda}-\left(\frac{1}{1+\varepsilon \lambda}\right) \int_{\underline{\underline{v}}(B(\bar{v}, r))}^{\bar{v}} F(x)^{n-1} d x
$$

defines $B(\bar{v}, r)$ implicitly. Third, although $B\left(v_{i}, r\right)$ is increasing in $v_{i}$ and in $r$, its comparative statics with respect to the number of bidders $(n)$, the strength of the reference point effect

\footnotetext{
${ }^{6}$ Other authors investigating auctions with buy prices obtain explicit expressions for the threshold buy price in their models. This is because the bidders in these models have reference-free preferences. In contrast, due to the reference-dependent preferences bidders have in our model, $B\left(v_{i}, r\right)$ becomes embedded in the lower bound of the of the integral on the right-hand side of equation (5). If instead we had bidders with reference-free preferences $(\varepsilon=0)$, we would have a threshold buy price of
}

$$
B\left(v_{i}, r\right)=v_{i}-\left(\frac{n\left(1-F\left(v_{i}\right)\right)}{1-F\left(v_{i}\right)^{n}}\right) \int_{r}^{v_{i}} F(x)^{n-1} d x
$$

which is precisely the expression for the threshold buy price in Mathews and Katzman (2006, p. 602). 
$(\varepsilon)$, and the weight bidders place on the auction's reserve price in formulating their reference price $(\lambda)$ are ambiguous. Finally, if bidders use only the auction's buy price to formulate their reference price, introducing a small reference-price effect causes $B\left(v_{i}, r\right)$ to decrease.

Proposition 3. Introducing a small reference-price effect causes a bidder's threshold buy price to decrease, that is,

$$
\left.\frac{d B\left(v_{i}, r\right)}{d \varepsilon}\right|_{\varepsilon=0}<0
$$

if $\lambda=0$.

If bidders use only the auction's buy price to formulate their reference price, then a transaction at the auction's buy price creates no extra gain for a bidder beyond the payoff from the difference between her valuation and her payment. Thus, when we introduce a small reference-price effect, bidders' threshold buy prices decrease and the range of buy prices any bidder is willing to exercise shrinks; that is, the threshold buy price shifts below the threshold buy price in a model where bidders have reference-free preferences as in, for example, Mathews and Katzman (2006), Seifert (2006), Ivanova-Stenzel and Kröger (2007) and Reynolds and Wooders (2007). If, instead, bidders use both the auction's buy price and its reserve price to formulate their reference price-in other words, if $\lambda \in(0,1)$-introducing a small reference-price effect has an ambiguous effect on bidders' threshold buy prices. Example 1 below suggests that, for $\lambda \in(0,1)$, small changes in the strength of the reference-price effect causes threshold buy prices to increase for relatively low valuation bidders and to decrease for relatively high valuation bidders.

Solving equation (5) for an explicit $B\left(v_{i}, r\right)$ is unnecessary for the analysis in this paper because only the shape of $B\left(v_{i}, r\right)$ matters for our present purposes. Nonetheless, in the following example, we present an explicit expression for the $B\left(v_{i}, r\right)$ that solves equation $(5)$.

Example 1. An explicit solution for $B\left(v_{i}, r\right)$. Consider the case of $n=2$ bidders whose valuations are distributed according to the Uniform distribution on $[0,1]$. In this case, $F\left(v_{i}\right)=$ $v_{i}, f\left(v_{i}\right)=1$, and equation (5) becomes

$$
B\left(v_{i}, r\right)=\frac{v_{i}+\varepsilon \lambda r}{1+\varepsilon \lambda}-\left(\frac{2\left(1-v_{i}\right)}{\left(1-v_{i}^{2}\right)(1+\varepsilon \lambda)}\right) \int_{\underline{\underline{v}}\left(B\left(v_{i}, r\right)\right)}^{v_{i}} x d x .
$$




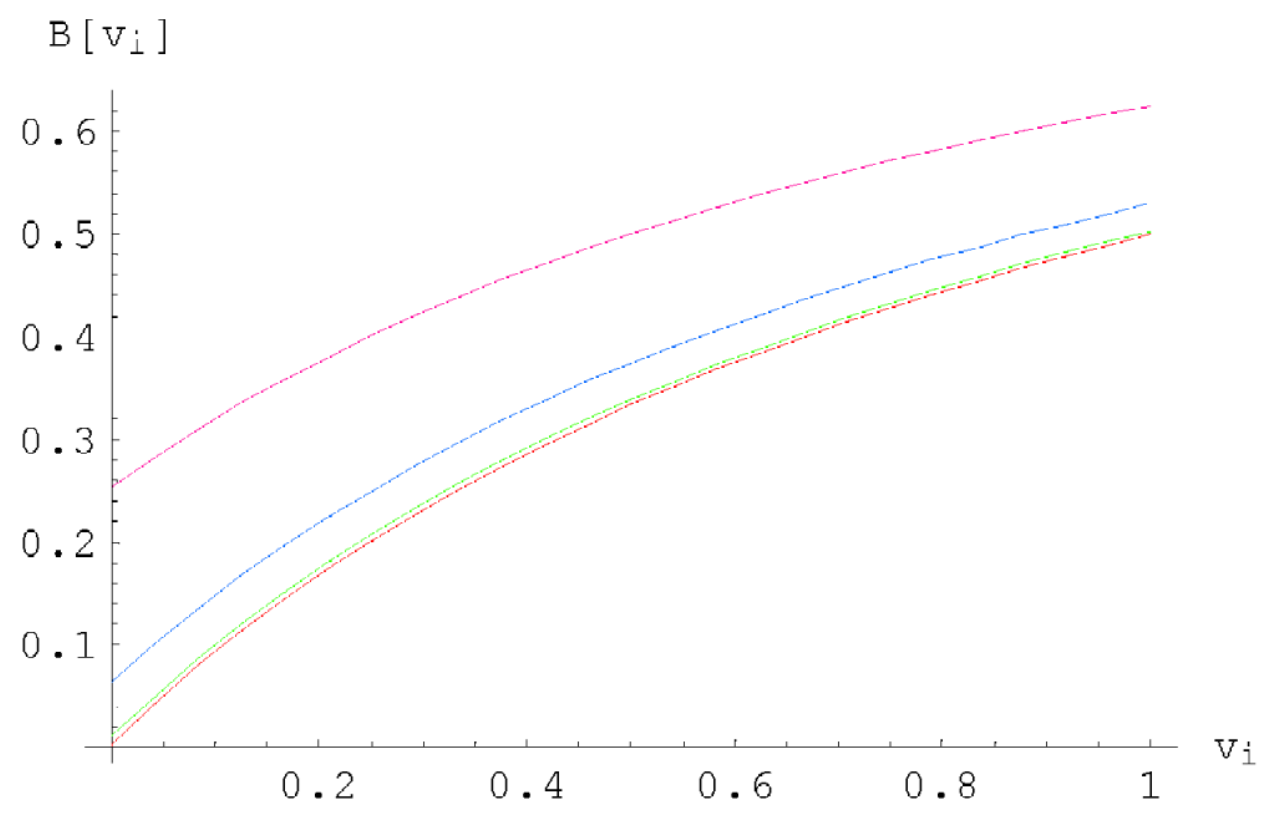

Figure 1: Threshold Buy Price for $\varepsilon=0.01, \lambda=0.5$, and $r=\{0.05,0.1,0.25,0.5\}$

The $B\left(v_{i}, r\right)$ that solves equation ( 7$)$ is

$$
\begin{aligned}
B\left(v_{i}, r\right)= & \frac{1+v_{i}+2 \varepsilon r+2 \varepsilon^{2} r+\varepsilon \lambda-2 \varepsilon \lambda r+\varepsilon \lambda v_{i}-4 \varepsilon^{2} \lambda r+2 \varepsilon^{2} \lambda^{2} r}{2 \varepsilon^{2}(\lambda-1)^{2}} \\
& -\frac{\sqrt{4 \varepsilon r(1+\varepsilon)(1-\lambda)+(1+\varepsilon \lambda)^{2}+\left(v_{i}+\varepsilon \lambda v_{i}\right)^{2}+}}{2 \varepsilon^{2}(\lambda-1)^{2}}
\end{aligned}
$$

Figure 1 contains a graph of this threshold buy price for $\varepsilon=0.01, \lambda=0.5$, and $r=$ $\{0.05,0.1,0.25,0.5\}$. The threshold buy price is concave and increasing in $v_{i}$ for a given $r$, and shifts upward as $r$ increases. Figure 2 contains a graph of this threshold buy price for $\varepsilon=\{0.01,0.1,0.25,0.5\}, \lambda=0.5$, and $r=0.5$. As Figure 2 makes clear, for a given $r$ and $\lambda$, the threshold buy price rotates clockwise as the strength of the reference-price effect increases. Thus, as the strength of the reference-price effect increases, the threshold buy prices of relatively low valuation bidders increase while those of relatively high valuation bidders decrease. Relatively low valuation bidders have a small probability of winning the second stage auction, and so when the strength of the reference-price effect increases, they are willing to exercise a larger range of of buy prices and thus forgo the second stage auction they have a relatively small likelihood of winning. The opposite is true of relatively high valuation bidders. 


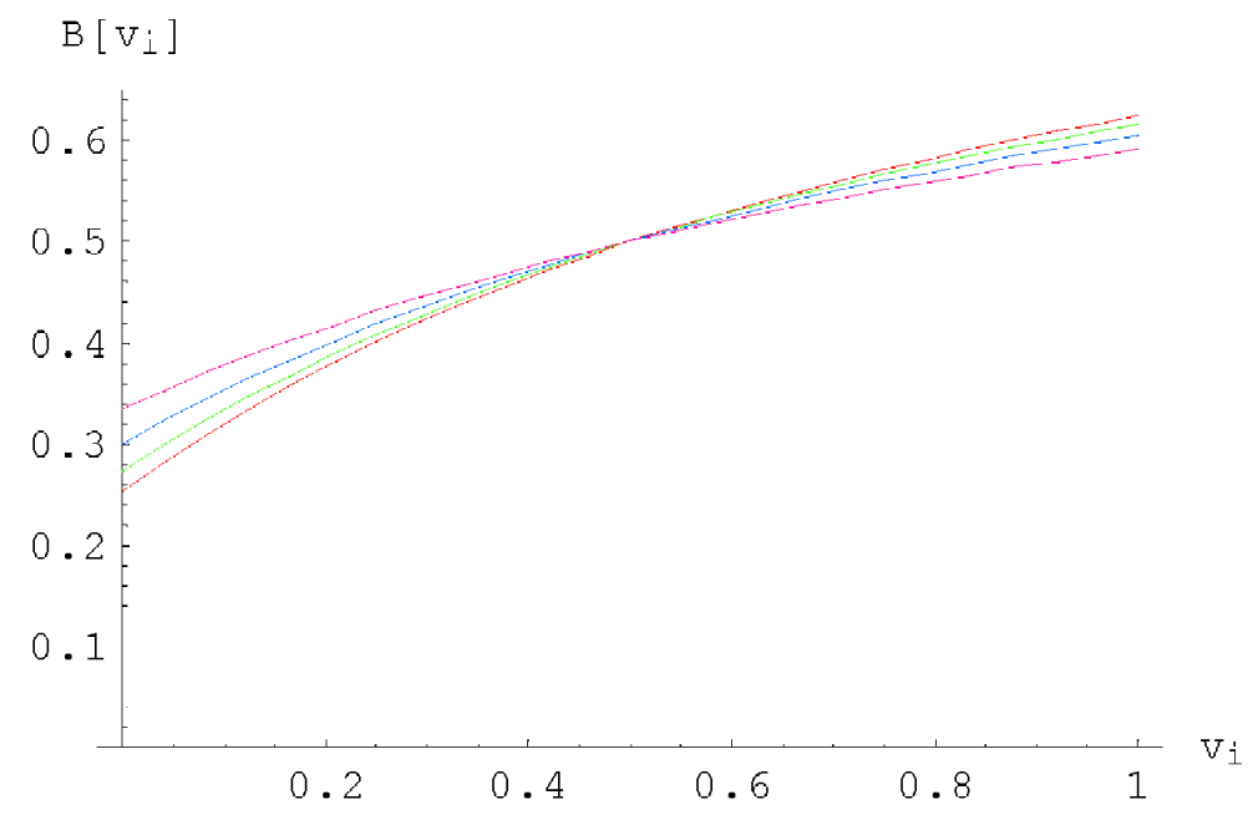

Figure 2: Threshold Buy Price for $\varepsilon=\{0.01,0.1,0.25,0.5\}, \lambda=0.5$, and $r=0.5$

\section{The Seller's Choice of $B^{*}$ and $r$}

How will a seller set her auction's buy price and reserve price when she anticipates bidders' equilibrium behavior? In particular, will a seller set a buy price so high that no bidder will accept it with positive probability in equilibrium? In models of auctions with a temporary buy price with risk-neutral bidders and a risk-neutral seller, a seller maximizes her revenue by setting a buy price so high that no bidder will accept the buy price with positive probability in equilibrium and instead will opt to compete in the auction (Mathews \& Katzman, 2006; Seifert, 2006; Ivanova-Stenzel \& Kröger, 2007; Reynolds \& Wooders, 2007). That is, a seller will set $B^{*}>B(\bar{v}, r)$. The argument behind this result is relatively straightforward. The optimal auction-in the sense of Myerson (1981) and Riley and Samuelson (1981)-features a reserve price $r_{0}$ that satisfies

$$
r_{0}=\frac{1-F\left(r_{0}\right)}{f\left(r_{0}\right)}
$$

and in which the seller allocates the good efficiently if it sells. In an auction with a buy price, the seller can implement the optimal auction by setting a reserve price to maximize her expected revenue and ensure the efficient allocation of the good if it sells by setting a buy price so high that no bidder will accept it with positive probability in equilibrium.

In our model, a seller would set a relatively high buy price, but would set a buy price that some bidder type would accept with positive probability in equilibrium. This 
result clearly contrasts with the finding that a risk-neutral seller facing risk-neutral bidders would set a buy price so high that no bidder would accept it with positive probability in equilibrium. Bidders are susceptible to the effects of a reference price, and a seller, anticipating this sensitivity, would set a high buy price to increase the bidders' reference prices and to encourage aggressive bidding in the second stage auction. Recall that, according to Proposition 1, the bid function

$$
\beta\left(v_{i}\right)=\frac{v_{i}+\varepsilon \rho}{1+\varepsilon}
$$

describes the equilibrium bidding behavior of a bidder of type $v_{i}$ in the second stage auction. Note that this bid function is linear and increasing in the reference price $\rho$ and, with $\rho=$ $\lambda r+(1-\lambda) B^{*}$, is linear and increasing in the buy price $B^{*}$. The seller, however, would not set a buy price so high that all bidder types would reject it in equilibrium. In particular, the seller would set a buy price such that $v^{*}<\bar{v}$, and thus the probability that some bidders exercise the buy price option in equilibrium is positive. The seller sets a buy price in this way to ensure a large payment if a bidder of type $v_{i}>v^{*}$ exercises the buy price in the first stage and to encourage all bidder types to bid aggressively in the second stage auction if it occurs.

Note that a seller does not know bidders' types, but does know the distribution of types and anticipates equilibrium behavior regarding the exercise of the buy price option and bidding in equilibrium. As is standard in the auction theory literature, we assume that the seller has no value for the item she sells and that her objective is to maximize her expected revenue from selling the item in an auction with a buy price. If the highest valuation bidder has a valuation below $v^{*}$, then the seller can expect a payment of the reserve price $r$ if only one bidder participates in the auction (i.e., if the second-highest valuation is below $\underline{\underline{v}}$ ) and can expect bidders to compete if the second-highest valuation is above $\underline{\underline{v}}$. If, however, the highest valuation bidder has a valuation above $v^{*}$, the seller can expect a payment of $B^{*}=B\left(v^{*}, r\right)$ since at least one bidder exercises the buy price option. When a seller anticipates bidders of type $v_{i}>v^{*}$ to exercise the buy price option in the first stage as we described in Proposition 2 and bidders of type $v_{i}$ to bid in the second stage according to the bid function $\beta\left(v_{i}\right)$ in Proposition 1 , her expected revenue takes the form

$$
R\left(v^{*}, r\right)=\int_{\underline{\underline{v}}}^{v^{*}}\left(\int_{\underline{\underline{v}}}^{\underline{\underline{v}}} r h(y \mid x) d y+\int_{\underline{\underline{v}}}^{x}\left(\frac{y+\varepsilon \rho}{1+\varepsilon}\right) h(y \mid x) d y\right) g(x) d x+\int_{v^{*}}^{\bar{v}} B\left(v^{*}, r\right) g(x) d x .
$$

We denote the highest valuation as $x$, the the second-highest valuation as $y$, the density 
of $x$ as $g(x)$, and the density of $y$ conditional on $x$ as $h(y \mid x)$. Because the $n$ bidders' valuations are $n$ independent draws from the distribution $F, g(x)=n F(x)^{n-1} f(x)$ and $h(y \mid x)=\frac{(n-1) F(y)^{n-2} f(y)}{F(x)^{n-1}}$.

We can rewrite the seller's expected revenue as

$$
\begin{aligned}
R\left(v^{*}, r\right)= & \int_{\underline{\underline{v}}}^{v^{*}}\left(\int_{\underline{\underline{v}}}^{\underline{\underline{v}}} r(n-1) F(y)^{n-2} f(y) d y+\int_{\underline{\underline{v}}}^{x}\left(\frac{y+\varepsilon \rho}{1+\varepsilon}\right)(n-1) F(y)^{n-2} f(y) d y\right) n f(x) d x \\
& +\int_{v^{*}}^{\bar{v}} B\left(v^{*}, r\right) n F(x)^{n-1} f(x) d x \\
= & r n F(\underline{\underline{v}})^{n-1}\left(F\left(v^{*}\right)-F(\underline{\underline{v}})\right)+\int_{\underline{\underline{v}}}^{v^{*}} \int_{\underline{\underline{v}}}^{x}\left(\frac{y+\varepsilon \rho}{1+\varepsilon}\right) n(n-1) F(y)^{n-2} f(y) d y f(x) d x \\
& +B\left(v^{*}, r\right)\left(1-F\left(v^{*}\right)^{n}\right) \\
= & r n F(\underline{\underline{v}})^{n-1}\left(F\left(v^{*}\right)-F(\underline{\underline{v}})\right)+\int_{\underline{\underline{v}}}^{v^{*}}\left(\frac{y+\varepsilon \rho}{1+\varepsilon}\right) n(n-1) F(y)^{n-2} f(y)\left(F\left(v^{*}\right)-F(y)\right) d y \\
& +B\left(v^{*}, r\right)\left(1-F\left(v^{*}\right)^{n}\right)
\end{aligned}
$$

(where the final equality follows from exchanging the order of integration in the double integral). We can analyze the seller's choice of the buy price and reserve price as a choice of $v^{*}$ and $r$, respectively, because $B\left(v^{*}, r\right)$ is increasing in $v^{*}$.

The following first derivatives of the expected revenue function characterize the seller's expected revenue-maximizing choices of $v^{*}$ and $r$ :

$$
\begin{aligned}
\frac{\partial R\left(v^{*}, r\right)}{\partial v^{*}}= & r n F(\underline{\underline{v}})^{n-1}\left(f\left(v^{*}\right)+f(\underline{\underline{v}}) \varepsilon(1-\lambda) \frac{\partial B\left(v^{*}, r\right)}{\partial v^{*}}\right) \\
& +\int_{\underline{\underline{v}}}^{v^{*}}\left(\frac{\varepsilon(1-\lambda) \frac{\partial B\left(v^{*}, r\right)}{\partial v^{*}}}{1+\varepsilon}\right) n(n-1) F(y)^{n-2} f(y)\left(F\left(v^{*}\right)-F(y)\right) d y \\
& +\int_{\underline{\underline{v}}}^{v^{*}}\left(\frac{y+\varepsilon \rho}{1+\varepsilon}\right) n(n-1) F(y)^{n-2} f(y) f\left(v^{*}\right) d y \\
& +\frac{\partial B\left(v^{*}, r\right)}{\partial v^{*}}\left(1-F\left(v^{*}\right)^{n}\right)-B\left(v^{*}, r\right) n F\left(v^{*}\right)^{n-1} f\left(v^{*}\right)
\end{aligned}
$$


and

$$
\begin{aligned}
\frac{\partial R\left(v^{*}, r\right)}{\partial r}= & n F(\underline{\underline{v}})^{n-1}\left(F\left(v^{*}\right)-F(\underline{\underline{v}})\right) \\
& -r n F(\underline{\underline{v}})^{n-1} f(\underline{\underline{v}})\left(1+\varepsilon-\varepsilon \lambda-\varepsilon(1-\lambda) \frac{\partial B\left(v^{*}, r\right)}{\partial r}\right) \\
& +\int_{\underline{\underline{v}}}^{v^{*}}\left(\frac{\left.\varepsilon \lambda+\varepsilon(1-\lambda) \frac{\partial B\left(v^{*}, r\right)}{\partial r}\right)}{1+\varepsilon}\right) n(n-1) F(y)^{n-2} f(y)\left(F\left(v^{*}\right)-F(y)\right) d y \\
& +\frac{\partial B\left(v^{*}, r\right)}{\partial r}\left(1-F\left(v^{*}\right)^{n}\right) .
\end{aligned}
$$

Analyzing equation (9) yields the following result.

Theorem 1. Given bidders' equilibrium strategies, a risk-neutral seller maximizes her expected revenue by setting some $v^{*}<\bar{v}$ and thus by posting a buy price of $B\left(v^{*}, r\right)<B(\bar{v}, r)$, a buy price that some bidder types would exercise with positive probability in equilibrium.

Recall that a bidder of type $v_{i}$ exercises the buy price option in equilibrium if and only if $B\left(v^{*}, r\right)<B\left(v_{i}, r\right)$ (equivalently, if and only if $v_{i}>v^{*}$ ). Thus, the probability that at least one bidder exercises the buy price option in equilibrium is the probability that at least one bidder is of type $v_{i}>v^{*}$, an event with probability $1-F\left(v^{*}\right)^{n}$ since the bidders' valuations are $n$ independent draws from $F$. Clearly, $1-F\left(v^{*}\right)^{n}>0$ as long as $v^{*}<\bar{v}$.

A seller will also set a buy price such that $B^{*}>r$. We can demonstrate this by evaluating equation (9) at $v^{*}=\underline{\underline{v}}$, a buy price of $B^{*}=r$. Note that

$$
\begin{aligned}
\left.\frac{\partial R\left(v^{*}, r\right)}{\partial v^{*}}\right|_{v^{*}=\underline{\underline{v}}}= & \left.\left(r n F(\underline{\underline{v}})^{n-1} f(\underline{\underline{v}}) \varepsilon(1-\lambda)\right) \frac{\partial B\left(v^{*}, r\right)}{\partial v^{*}}\right|_{v^{*}=\underline{\underline{v}}} \\
& +\left.\left(1-F(\underline{\underline{v}})^{n}\right) \frac{\partial B\left(v^{*}, r\right)}{\partial v^{*}}\right|_{v^{*}=\underline{\underline{v}}} \\
> & 0,
\end{aligned}
$$

and thus $B^{*}>r$ for all $r \in[\underline{v}, \bar{v})$. The fact that $B^{*}>r$ illustrates that a seller in this model does not want to sell her good at a posted price of $r$, but instead prefers to augment her auction with a buy price.

When bidders formulate their reference price using both the auction's reserve price and its buy price, the seller sets a higher reserve price than she would set when she can affect the bidders' reference price through the auction's reserve price only. That is, the reserve price a seller sets in our model exceeds the one she would set in the model of Rosenkrantz and Schmitz (2007) where bidders use the auction's reserve price and some exogenous price $x$ to 
formulate their reference price. Let $r_{x}$ denote the expected revenue-maximizing reserve price a seller would set if the bidders' reference price were $\rho=\lambda r+(1-\lambda) x$ with $\lambda \in(0,1)$.

Theorem 2. Given bidders' equilibrium strategies and the formulation of their reference price as a convex combination of the auction's reserve price and buy price, a risk-neutral seller maximizes her expected revenue by setting $r>r_{x}$ and thus by setting a reserve price that exceeds the reserve price she would set if the bidders' reference price were a convex combination of the auction's reserve price and some exogenous price holding bidders' participation decisions fixed.

To get a sense of the result in Theorem 2, hold the bidders' participation condition $\underline{\underline{v}}$ and the seller's choice of $v^{*}$ fixed, and note that under these conditions $r_{x}$ satisfies the first-order condition

$$
\begin{aligned}
n F(\underline{\underline{v}})^{n-1}\left(F\left(v^{*}\right)-F(\underline{\underline{v}})\right) & -r_{x} n F(\underline{\underline{v}})^{n-1} f(\underline{\underline{v}})(1+\varepsilon-\varepsilon \lambda) \\
& +\int_{\underline{\underline{v}}}^{v^{*}}\left(\frac{\varepsilon \lambda}{1+\varepsilon}\right) n(n-1) F(y)^{n-2} f(y)\left(F\left(v^{*}\right)-F(y)\right) d y=0 .
\end{aligned}
$$

When we evaluate equation (10) at $r=r_{x}$, we have

$$
\begin{aligned}
\left.\frac{\partial R\left(v^{*}, r\right)}{\partial r}\right|_{r=r_{x}}= & n F(\underline{\underline{v}})^{n-1}\left(F\left(v^{*}\right)-F(\underline{\underline{v}})\right) \\
& -r_{x} n F(\underline{\underline{v}})^{n-1} f(\underline{\underline{v}})\left(1+\varepsilon-\varepsilon \lambda-\varepsilon(1-\lambda) \frac{\partial B\left(v^{*}, r_{x}\right)}{\partial r}\right) \\
& +\int_{\underline{\underline{v}}}^{v^{*}}\left(\frac{\left.\varepsilon \lambda+\varepsilon(1-\lambda) \frac{\partial B\left(v^{*}, r_{x}\right)}{\partial r}\right)}{1+\varepsilon}\right) n(n-1) F(y)^{n-2} f(y)\left(F\left(v^{*}\right)-F(y)\right) d y \\
& +\frac{\partial B\left(v^{*}, r_{x}\right)}{\partial r}\left(1-F\left(v^{*}\right)^{n}\right) \\
> & n F(\underline{\underline{v}})^{n-1}\left(F\left(v^{*}\right)-F(\underline{\underline{v}})\right)-r_{x} n F(\underline{\underline{v}})^{n-1} f(\underline{\underline{v}})(1+\varepsilon-\varepsilon \lambda) \\
& +\int_{\underline{\underline{v}}}^{v^{*}}\left(\frac{\varepsilon \lambda}{1+\varepsilon}\right) n(n-1) F(y)^{n-2} f(y)\left(F\left(v^{*}\right)-F(y)\right) d y \\
= & 0
\end{aligned}
$$

(where the inequality follows from the fact that $B\left(v_{i}, r\right)$ is increasing in $r$ ). Thus, we have $\left.\frac{\partial R\left(v^{*}, r\right)}{\partial r}\right|_{r=r_{x}}>0$, which implies that the seller will set $r>r_{x}$. Holding fixed $\underline{\underline{v}}$ and $v^{*}$, when we move from a world in which the seller can affect the bidders' reference price through her auction's reserve price only to a world in which she can affect the bidders' reference price through her auction's reserve price (direct effect) and buy price (indirect effect), the seller 
gains an added benefit from setting a higher reserve price, and thus we see that $r>r_{x}$. Of course, the seller's choice of $v^{*}$ does change when $\rho=\lambda r+(1-\lambda) x$, and this change in $v^{*}$ could eliminate any extra benefit to the seller from setting a higher reserve price, but the proof of Theorem 2 accounts for this and reveals otherwise. ${ }^{7}$

\section{Conclusion}

We study a model of an auction with a temporary buy price in which bidders have referencedependent preferences and utilize the auction's reserve price and buy price to formulate their reference price. After establishing the existence and uniqueness of equilibrium in the model, we find that bidders' reference-dependence provides a seller with a rationale for augmenting her auction with a buy price even when both the bidders and the seller are risk-neutral. Further, we find that when the bidders' reference price depends upon both the auction's reserve price and its buy price, the seller sets a higher reserve price than when she can affect the bidders' reference price through the auction's reserve price only. We also note how bidders' equilibrium behavior differs from behavior in the standard model by demonstrating that introducing a small reference-price effect shrinks the range of buy prices bidders are willing to exercise when they use the auction's buy price as their reference price. The comparative statics properties of equilibrium bidding behavior in the model contrast with other models of auctions with a buy price where the existence and size of the auction's buy price have no effect on bidding behavior. Further, that the auction's reserve price and buy price affect equilibrium bidding behavior in a predictable way accords well with evidence from the laboratory and from the field that bidders have reference-dependent preferences and utilize auctions' reserve prices, buy prices, and other posted prices (e.g., closing prices of earlier or adjacent auctions) to formulate their reference price.

There are a number of other interesting avenues for further research. The model we study in this paper could be generalized to account for bidders with heterogeneous reference prices (or strength of the reference-price effect) or for bidders that arrive to an auction at different times and who thus might not observe the auction's buy price if another bidder chose to submit a bid. One could easily extend the present model to auctions with a permanent buy price and study how bidders' behavior differs from the equilibrium behavior Hidvégi

\footnotetext{
${ }^{7}$ Theorem 1 establishes that $v^{*}<\bar{v}$, but when $\rho=\lambda r+(1-\lambda) x$, the result from Mathews and Katzman (2006, Theorem 1) implies that $v^{*}=\bar{v}$. The proof of Theorem 2 accounts for the fact that a seller would set $v^{*}=\bar{v}$ when she can affect the bidders' reference price through her auction's reserve price only and still finds that the seller would increase her auction's reserve price when she can affect the bidders' reference price through her auction's reserve price and buy price.
} 
et al. (2006) and Reynolds and Wooders (2007) describe. Finally, more laboratory and field experiments like those of Grebe et al. (2006), Seifert (2006), Shahriar and Wooders (2006), and Popkowski Leszczyc et al. (2007) can provide insights into bidder and seller behavior in auctions with a buy price. 


\section{Appendix}

Proof of Proposition 1. The critical valuation $\underline{\underline{v}}$ for participation has the expression $\underline{\underline{v}}=$ $(1+\varepsilon) r-\varepsilon \rho$ because the minimum price a bidder can expect to pay in the auction is the reserve price $r$, and thus a bidder with valuation $\underline{\underline{v}}$ is just indifferent between participating in the auction and paying the reserve price and not participating in the auction.

Suppose that all bidders with $v_{i} \geq \underline{\underline{v}}$ bid according to the proposed equilibrium strategy in equation (1), and suppose that bidder $i$ considers a unilateral deviation to some $\tilde{b}<\beta\left(v_{i}\right)$. Let $x$ denote the amount of the highest rival bid that bidder $i$ faces and suppose that the seller breaks ties at random. If $x \leq \tilde{b}<\beta\left(v_{i}\right)$, bidder $i$ now risks losing the auction but her payment does not change. If $\tilde{b}<\beta\left(v_{i}\right) \leq x$, bidder $i$ now loses the auction. Finally, if $\tilde{b} \leq x<\beta\left(v_{i}\right)$, bidder $i$ now risks losing what would have been a profitable opportunity. Therefore, bidder $i$ has no incentive to deviate unilaterally to some $\tilde{b}<\beta\left(v_{i}\right)$ when the other bidders play their equilibrium strategies. We can demonstrate with an analogous argument that bidder $i$ has no incentive to deviate unilaterally to some $\tilde{b}>\beta\left(v_{i}\right)$ when the other bidders play their equilibrium strategies.

Lemma 1. $B\left(v_{i}, r\right)$ is increasing in $v_{i}$ and in $r$.

Proof of Lemma 1. Recall that the equation

$$
B\left(v_{i}, r\right)=\frac{v_{i}+\varepsilon \lambda r}{1+\varepsilon \lambda}-\left(\frac{n\left(1-F\left(v_{i}\right)\right)}{\left(1-F\left(v_{i}\right)^{n}\right)(1+\varepsilon \lambda)}\right) \int_{\underline{\underline{v}}\left(B\left(v_{i}, r\right)\right)}^{v_{i}} F(x)^{n-1} d x
$$

defines $B\left(v_{i}, r\right)$ implicitly. From implicit differentiation, it follows that

$$
\begin{aligned}
\frac{d B\left(v_{i}, r\right)}{d v_{i}} & =\frac{\left.\left(\frac{1-n F\left(v_{i}\right)^{n-1}+(n-1) F\left(v_{i}\right)^{n}}{\left(1-F\left(v_{i}\right)^{n}\right)(1+\varepsilon \lambda)}\right)+\left(\frac{n f\left(v_{i}\right)(1+\varepsilon \lambda)\left(1-n F\left(v_{i}\right)^{n-1}+(n-1) F\left(v_{i}\right)^{n}\right)}{\left[\left(1-F\left(v_{i}\right)\right.\right.}\right) \int_{\underline{\underline{v}}}^{v_{i}} F(1+\varepsilon \lambda)\right]^{2}}{1+\left(\frac{n\left(1-F\left(v_{i}\right)\right) F(\underline{\underline{v}})^{n-1} \varepsilon(1-\lambda)}{\left(1-F\left(v_{i}\right)^{n}\right)(1+\varepsilon \lambda)}\right)} d x \\
& >0
\end{aligned}
$$

because $1-n F\left(v_{i}\right)^{n-1}+(n-1) F\left(v_{i}\right)^{n}>0$ as long as $F\left(v_{i}\right)<1$. From implicit differentiation, it also follows that

$$
\frac{d B\left(v_{i}, r\right)}{d r}=\frac{\varepsilon \lambda+\left(\frac{n\left(1-F\left(v_{i}\right)\right) F(\underline{\underline{v}})^{n-1}(1+\varepsilon-\varepsilon \lambda)}{1-F\left(v_{i}\right)^{n}}\right)}{1+\varepsilon \lambda+\left(\frac{n\left(1-F\left(v_{i}\right)\right) F(\underline{\underline{v}})^{n-1} \varepsilon(1-\lambda)}{1-F\left(v_{i}\right)^{n}}\right)}>0
$$

Proof of Proposition 2. Consider bidders in an auction with a buy price $B^{*}$ and a reserve 
price $r$. We will show that if all other bidders accept the buy price if and only if their valuations exceed the critical valuation $v^{*}$, a bidder of type $v_{i}$ will prefer to do the same. Recall that the critical valuation $v^{*}$ satisfies $B\left(v^{*}, r\right)=B^{*}$ and that the equation

$$
B\left(v_{i}, r\right)=\frac{v_{i}+\varepsilon \lambda r}{1+\varepsilon \lambda}-\left(\frac{n\left(1-F\left(v_{i}\right)\right)}{\left(1-F\left(v_{i}\right)^{n}\right)(1+\varepsilon \lambda)}\right) \int_{\underline{\underline{v}}\left(B\left(v_{i}, r\right)\right)}^{v_{i}} F(x)^{n-1} d x
$$

defines $B\left(v_{i}, r\right)$ implicitly.

When all other bidders follow the equilibrium strategy, a bidder of type $v_{i}$ 's expected payoff from forgoing the buy price and competing in the auction is

$$
\begin{aligned}
\pi^{A}\left(v_{i}, v^{*}\right)= & \left(v_{i}-r-\varepsilon(r-\rho)\right) F(\underline{\underline{v}})^{n-1} \\
& +\int_{\underline{\underline{v}}}^{\min \left\{v_{i}, v^{*}\right\}}\left(v_{i}-\frac{x+\varepsilon \rho}{1+\varepsilon}-\varepsilon\left(\frac{x+\varepsilon \rho}{1+\varepsilon}-\rho\right)\right)(n-1) F(x)^{n-2} f(x) d x \\
= & \left(v_{i}-r-\varepsilon(r-\rho)\right) F(\underline{\underline{v}})^{n-1}+\int_{\underline{\underline{v}}}^{\min \left\{v_{i}, v^{*}\right\}}\left(v_{i}-x\right)(n-1) F(x)^{n-2} f(x) d x \\
= & \left(v_{i}-\min \left\{v_{i}, v^{*}\right\}\right) F\left(\min \left\{v_{i}, v^{*}\right\}\right)^{n-1}+\int_{\underline{\underline{v}}}^{\min \left\{v_{i}, v^{*}\right\}} F(x)^{n-1} d x
\end{aligned}
$$

(where the final equality follows from integration by parts).

On the other hand, when all other bidders follow the equilibrium strategy, a bidder of type $v_{i}$ 's expected payoff from exercising the buy price option is

$$
\begin{aligned}
\pi^{B}\left(v_{i}, v^{*}\right) & =\sum_{k=0}^{n-1}\left(\begin{array}{c}
n-1 \\
k
\end{array}\right) F\left(v^{*}\right)^{n-k-1}\left(1-F\left(v^{*}\right)\right)^{k} \frac{1}{1+k}\left(v_{i}-B^{*}-\varepsilon\left(B^{*}-\rho\right)\right) \\
& =\left(\frac{1-F\left(v^{*}\right)^{n}}{n\left(1-F\left(v^{*}\right)\right)}\right)\left(v_{i}-B^{*}-\varepsilon\left(B^{*}-\rho\right)\right) .
\end{aligned}
$$

We can write Newton's Binomial Formula as $\sum_{i=0}^{n}\left(\begin{array}{c}n \\ i\end{array}\right) x^{n-i} y^{i}=(x+y)^{n}$, from which follows $\sum_{k=0}^{n-1}\left(\begin{array}{c}n-1 \\ k\end{array}\right) \frac{x^{n-k-1} y^{k}}{1+k}=\frac{(x+y)^{n}-x^{n}}{n y}$. When we define $x=F\left(v^{*}\right)$ and $y=1-F\left(v^{*}\right)$, we obtain the desired result.

A necessary condition for equilibrium is for a bidder of type $v^{*}$ to be indifferent between competing in the auction and exercising the buy price $B^{*}$; that is, we must have $\pi^{A}\left(v^{*}, v^{*}\right)=$ $\pi^{B}\left(v^{*}, v^{*}\right)$. The equality of expected payoffs for a bidder of type $v^{*}$ implies that

$$
\int_{\underline{\underline{v}}}^{v^{*}} F(x)^{n-1} d x=\left(\frac{1-F\left(v^{*}\right)^{n}}{n\left(1-F\left(v^{*}\right)\right)}\right)\left(v^{*}-B^{*}-\varepsilon\left(B^{*}-\rho\right)\right),
$$


which in turn implies that

$$
B^{*}=\frac{v^{*}+\varepsilon \lambda r}{1+\varepsilon \lambda}-\left(\frac{n\left(1-F\left(v^{*}\right)\right)}{\left(1-F\left(v^{*}\right)^{n}\right)(1+\varepsilon \lambda)}\right) \int_{\underline{\underline{v}}\left(B^{*}\right)}^{v^{*}} F(x)^{n-1} d x .
$$

With $B\left(v_{i}, r\right)=\frac{v_{i}+\varepsilon \lambda r}{1+\varepsilon \lambda}-\left(\frac{n\left(1-F\left(v_{i}\right)\right)}{\left(1-F\left(v_{i}\right)^{n}\right)(1+\varepsilon \lambda)}\right) \int_{\underline{\underline{v}}\left(B\left(v_{i}, r\right)\right)}^{v_{i}} F(x)^{n-1} d x$, the condition holds for $B^{*}=$ $B\left(v^{*}, r\right)$.

Note that $\frac{d \pi^{A}\left(v_{i}, v^{*}\right)}{d v_{i}}=F\left(\min \left\{v_{i}, v^{*}\right\}\right)^{n-1} \leq F\left(v^{*}\right)^{n-1}$ and that $\frac{d \pi^{B}\left(v_{i}, v^{*}\right)}{d v_{i}}=\frac{1-F\left(v^{*}\right)^{n}}{n\left(1-F\left(v^{*}\right)\right)}$. Therefore,

$$
\begin{aligned}
\frac{d \pi^{A}\left(v_{i}, v^{*}\right)}{d v_{i}}-\frac{d \pi^{B}\left(v_{i}, v^{*}\right)}{d v_{i}} & \leq F\left(v^{*}\right)^{n-1}-\frac{1-F\left(v^{*}\right)^{n}}{n\left(1-F\left(v^{*}\right)\right)} \\
& =\frac{-\left(1-n F\left(v^{*}\right)^{n-1}+(n-1) F\left(v^{*}\right)^{n}\right)}{n\left(1-F\left(v^{*}\right)\right)} \\
& <0
\end{aligned}
$$

because $1-n F\left(v^{*}\right)^{n-1}+(n-1) F\left(v^{*}\right)^{n}>0$ as long as $F\left(v^{*}\right)<1$, and so $\frac{d \pi^{B}\left(v_{i}, v^{*}\right)}{d v_{i}}>\frac{d \pi^{A}\left(v_{i}, v^{*}\right)}{d v_{i}}$. Since $\pi^{A}\left(v_{i}, v^{*}\right)=\pi^{B}\left(v_{i}, v^{*}\right)$ at $v_{i}=v^{*}$, we must have $\pi^{A}\left(v_{i}, v^{*}\right)>\pi^{B}\left(v_{i}, v^{*}\right)$ for $v_{i}<v^{*}$ and $\pi^{B}\left(v_{i}, v^{*}\right)>\pi^{A}\left(v_{i}, v^{*}\right)$ for $v_{i}>v^{*}$.

To see that this symmetric equilibrium is unique, note that because $B\left(v_{i}, r\right)$ is increasing in $v_{i}$ (by Lemma 1 ), the existence of some $\hat{v} \neq v^{*}$ satisfying $B(\hat{v}, r)=B^{*}$ would lead to a contradiction.

Proof of Proposition 3. Recall that the equation

$$
B\left(v_{i}, r\right)=\frac{v_{i}+\varepsilon \lambda r}{1+\varepsilon \lambda}-\left(\frac{n\left(1-F\left(v_{i}\right)\right)}{\left(1-F\left(v_{i}\right)^{n}\right)(1+\varepsilon \lambda)}\right) \int_{\underline{\underline{v}}\left(B\left(v_{i}, r\right)\right)}^{v_{i}} F(x)^{n-1} d x
$$

defines $B\left(v_{i}, r\right)$ implicitly. From implicit differentiation, it follows that

$$
\frac{d B\left(v_{i}, r\right)}{d \varepsilon}=\frac{-\left(\frac{\left(v_{i}-r\right) \lambda}{(1+\varepsilon \lambda)^{2}}\right)+\left(\frac{n\left(1-F\left(v_{i}\right)\right) \lambda}{\left(1-F\left(v_{i}\right)^{n}\right)(1+\varepsilon \lambda)^{2}}\right) \int_{\underline{\underline{v}}}^{v_{i}} F(x)^{n-1} d x+\left(\frac{n\left(1-F\left(v_{i}\right)\right)}{\left(1-F\left(v_{i}\right)^{n}\right)(1+\varepsilon \lambda)}\right) F(\underline{\underline{v}})^{n-1}(r-\rho)}{1+\left(\frac{n\left(1-F\left(v_{i}\right)\right) F(\underline{\underline{v}})^{n-1} \varepsilon(1-\lambda)}{\left(1-F\left(v_{i}\right)^{n}\right)(1+\varepsilon \lambda)}\right)},
$$

and

$\left.\frac{d B\left(v_{i}, r\right)}{d \varepsilon}\right|_{\varepsilon=0}=-\left(v_{i}-r\right) \lambda+\left(\frac{n\left(1-F\left(v_{i}\right)\right) \lambda}{1-F\left(v_{i}\right)^{n}}\right) \int_{r}^{v_{i}} F(x)^{n-1} d x+\left(\frac{n\left(1-F\left(v_{i}\right)\right)}{1-F\left(v_{i}\right)^{n}}\right) F(r)^{n-1}(r-\rho)$, 
which is ambiguous in sign. However, for $\lambda=0$, we have

$$
\left.\frac{d B\left(v_{i}, r\right)}{d \varepsilon}\right|_{\varepsilon=0, \lambda=0}=\left(\frac{n\left(1-F\left(v_{i}\right)\right)}{1-F\left(v_{i}\right)^{n}}\right) F(r)^{n-1}\left(r-B\left(v_{i}, r\right)\right)<0 .
$$

Thus, when $\lambda=0$, introducing a small reference-price effect causes bidders' threshold buy prices to decrease and the range of buy prices any bidder is willing to exercise shrinks.

Proof of Theorem 1. Recall that the following first derivatives of the expected revenue function characterize the seller's expected revenue-maximizing choices of $v^{*}$ and $r$ :

$$
\begin{aligned}
\frac{\partial R\left(v^{*}, r\right)}{\partial v^{*}}= & r n F(\underline{\underline{v}})^{n-1}\left(f\left(v^{*}\right)+f(\underline{\underline{v}}) \varepsilon(1-\lambda) \frac{\partial B\left(v^{*}, r\right)}{\partial v^{*}}\right) \\
& +\int_{\underline{\underline{v}}}^{v^{*}}\left(\frac{\varepsilon(1-\lambda) \frac{\partial B\left(v^{*}, r\right)}{\partial v^{*}}}{1+\varepsilon}\right) n(n-1) F(y)^{n-2} f(y)\left(F\left(v^{*}\right)-F(y)\right) d y \\
& +\int_{\underline{\underline{v}}}^{v^{*}}\left(\frac{y+\varepsilon \rho}{1+\varepsilon}\right) n(n-1) F(y)^{n-2} f(y) f\left(v^{*}\right) d y \\
& +\frac{\partial B\left(v^{*}, r\right)}{\partial v^{*}}\left(1-F\left(v^{*}\right)^{n}\right)-B\left(v^{*}, r\right) n F\left(v^{*}\right)^{n-1} f\left(v^{*}\right)
\end{aligned}
$$

and

$$
\begin{aligned}
\frac{\partial R\left(v^{*}, r\right)}{\partial r}= & n F(\underline{\underline{v}})^{n-1}\left(F\left(v^{*}\right)-F(\underline{\underline{v}})\right) \\
& -r n F(\underline{\underline{v}})^{n-1} f(\underline{\underline{v}})\left(1+\varepsilon-\varepsilon \lambda-\varepsilon(1-\lambda) \frac{\partial B\left(v^{*}, r\right)}{\partial r}\right) \\
& +\int_{\underline{\underline{v}}}^{v^{*}}\left(\frac{\varepsilon \lambda+\varepsilon(1-\lambda) \frac{\partial B\left(v^{*}, r\right)}{\partial r}}{1+\varepsilon}\right) n(n-1) F(y)^{n-2} f(y)\left(F\left(v^{*}\right)-F(y)\right) d y \\
& +\frac{\partial B\left(v^{*}, r\right)}{\partial r}\left(1-F\left(v^{*}\right)^{n}\right) .
\end{aligned}
$$

We can demonstrate the desirability of setting $v^{*}<\bar{v}$ by showing that while $\left.\frac{\partial R\left(v^{*}, r\right)}{\partial v^{*}}\right|_{v^{*}=\bar{v}}=0$ for all $r \in[\underline{v}, \bar{v}),\left.\frac{\partial^{2} R\left(v^{*}, r\right)}{\partial v^{* 2}}\right|_{v^{*}=\bar{v}}>0$ for all $r \in[\underline{v}, \bar{v})$. 
Note that

$$
\begin{aligned}
\left.\frac{\partial R\left(v^{*}, r\right)}{\partial v^{*}}\right|_{v^{*}=\bar{v}}= & \operatorname{rnF}(\underline{\underline{v}})^{n-1}\left(f(\bar{v})+\left.f(\underline{\underline{v}}) \varepsilon(1-\lambda) \frac{\partial B\left(v^{*}, r\right)}{\partial v^{*}}\right|_{v^{*}=\bar{v}}\right) \\
& +\int_{\underline{\underline{v}}}^{\bar{v}}\left(\frac{\left.\varepsilon(1-\lambda) \frac{\partial B\left(v^{*}, r\right)}{\partial v^{*}}\right|_{v^{*}=\bar{v}}}{1+\varepsilon} n(n-1) F(y)^{n-2} f(y)(1-F(y)) d y\right. \\
& +\int_{\underline{\underline{v}}}\left(\frac{y+\varepsilon \rho}{1+\varepsilon}\right) n(n-1) F(y)^{n-2} f(y) f(\bar{v}) d y+B(\bar{v}, r) n f(\bar{v}) \\
= & r n F(\underline{\underline{v}})^{n-1} f(\bar{v})+\int_{\underline{\underline{v}}}^{\bar{v}}\left(\frac{y+\varepsilon \rho}{1+\varepsilon}\right) n(n-1) F(y)^{n-2} f(y) f(\bar{v}) d y \\
& +B(\bar{v}, r) n f(\bar{v})
\end{aligned}
$$

since $\left.\frac{\partial B\left(v^{*}, r\right)}{\partial v^{*}}\right|_{v^{*}=\bar{v}}=0$. When $r=\bar{v}, \underline{\underline{v}}=\bar{v}, B(\bar{v}, \bar{v})=\bar{v}$, and, thus, $\left.\frac{\partial R\left(v^{*}, r\right)}{\partial v^{*}}\right|_{v^{*}=\bar{v}}=0$.

Further, note that

$$
\begin{aligned}
\frac{\partial}{\partial r}\left(\left.\frac{\partial R\left(v^{*}, r\right)}{\partial v^{*}}\right|_{v^{*}=\bar{v}}\right)= & n F(\underline{\underline{v}})^{n-1} f(\bar{v}) \\
& +\left(\frac{\varepsilon \lambda+\varepsilon(1-\lambda) \frac{\partial B(\bar{v}, r)}{\partial r}}{1+\varepsilon}\right)\left(1-F(\underline{\underline{v}})^{n-1}\right) n f(\bar{v}) \\
& -\frac{\partial B(\bar{v}, r)}{\partial r} n f(\bar{v}) \\
= & 0
\end{aligned}
$$

since $\frac{\partial B(\bar{v}, r)}{\partial r}=\frac{\varepsilon \lambda+F(\underline{\underline{v}})^{n-1}(1+\varepsilon-\varepsilon \lambda)}{1+\varepsilon \lambda+F(\underline{\underline{v}})^{n-1} \varepsilon(1-\lambda)}$.

Therefore, we must have $\left.\frac{\partial R\left(v^{*}, r\right)}{\partial v^{*}}\right|_{v^{*}=\bar{v}}=0$ for all $r \in[\underline{v}, \bar{v})$ since $\left.\frac{\partial R\left(v^{*}, r\right)}{\partial v^{*}}\right|_{v^{*}=\bar{v}}=0$ is independent of $r$ and is zero for $r=\bar{v}$.

The seller's expected revenue, however, attains a maximum at some $v^{*}<\bar{v}$ because 


$$
\begin{aligned}
\left.\frac{\partial^{2} R\left(v^{*}, r\right)}{\partial v^{* 2}}\right|_{v^{*}=\bar{v}}> & 0 \text { for all } r \in[\underline{v}, \bar{v}) \text {. To see this, note that } \\
\frac{\partial^{2} R\left(v^{*}, r\right)}{\partial v^{* 2}=} & -r n(n-1) F(\underline{\underline{v}})^{n-2}\left(f(\underline{\underline{v}}) \varepsilon(1-\lambda) \frac{\partial B\left(v^{*}, r\right)}{\partial v^{*}}\right)^{2} \\
& +r n F(\underline{\underline{v}})^{n-1}\left(f^{\prime}\left(v^{*}\right)-f^{\prime}(\underline{\underline{v}})\left(\varepsilon(1-\lambda) \frac{\partial B\left(v^{*}, r\right)}{\partial v^{*}}\right)^{2}+f(\underline{\underline{v}}) \varepsilon(1-\lambda) \frac{\partial^{2} B\left(v^{*}, r\right)}{\partial v^{* 2}}\right) \\
& +\int_{\underline{\underline{v}}}^{v^{*}}\left(\frac{\varepsilon(1-\lambda) \frac{\partial^{2} B\left(v^{*}, r\right)}{\partial v^{* 2}}}{1+\varepsilon}\right) n(n-1) F(y)^{n-2} f(y)\left(F\left(v^{*}\right)-F(y)\right) d y \\
& +2 \int_{\underline{\underline{v}}}^{v^{*}}\left(\frac{\varepsilon(1-\lambda) \frac{\partial B\left(v^{*}, r\right)}{\partial v^{*}}}{1+\varepsilon}\right) n(n-1) F(y)^{n-2} f(y) f\left(v^{*}\right) d y \\
& +\left(\frac{\left(\varepsilon(1-\lambda) \frac{\partial B\left(v^{*}, r\right)}{\partial v^{*}}\right)^{2}}{1+\varepsilon}\right) n(n-1) F(\underline{\underline{v}})^{n-2} f(\underline{\underline{v}})\left(F\left(v^{*}\right)-F(\underline{\underline{v}})\right) \\
& +\int_{\underline{\underline{v}}}^{v^{*}}\left(\frac{y+\varepsilon \rho}{1+\varepsilon}\right) n(n-1) F(y)^{n-2} f(y) f^{\prime}\left(v^{*}\right) d y \\
& +\left(\frac{v^{*}+\varepsilon \rho}{1+\varepsilon}\right) n(n-1) F\left(v^{*}\right)^{n-2} f\left(v^{*}\right)^{2}+\frac{\partial^{2} B\left(v^{*}, r\right)}{\partial v^{* 2}}\left(1-F\left(v^{*}\right)^{n}\right) \\
& -2 \frac{\partial B\left(v^{*}, r\right)}{\partial v^{*}} n F\left(v^{*}\right)^{n-1} f\left(v^{*}\right)-B\left(v^{*}, r\right) n(n-1) F\left(v^{*}\right)^{n-2} f\left(v^{*}\right)^{2} \\
& -B\left(v^{*}, r\right) n F\left(v^{*}\right)^{n-1} f^{\prime}\left(v^{*}\right),
\end{aligned}
$$

and, for $v^{*}=\bar{v}$, we have

$$
\begin{aligned}
\left.\frac{\partial^{2} R\left(v^{*}, r\right)}{\partial v^{* 2}}\right|_{v^{*}=\bar{v}}= & r n F(\underline{\underline{v}})^{n-1} f^{\prime}(\bar{v})+\int_{\underline{\underline{v}}}^{\bar{v}}\left(\frac{y+\varepsilon \rho}{1+\varepsilon}\right) n(n-1) F(y)^{n-2} f(y) f^{\prime}(\bar{v}) d y \\
& +\left(\frac{\bar{v}+\varepsilon \rho}{1+\varepsilon}\right) n(n-1) f(\bar{v})^{2}-B(\bar{v}, r) n(n-1) f(\bar{v})^{2}-B(\bar{v}, r) n f^{\prime}(\bar{v})
\end{aligned}
$$

since $\left.\frac{\partial B\left(v^{*}, r\right)}{\partial v^{*}}\right|_{v^{*}=\bar{v}}=0$ and $\left.\frac{\partial^{2} B\left(v^{*}, r\right)}{\partial v^{* 2}}\right|_{v^{*}=\bar{v}}=0$. When $r=\bar{v}, \underline{\underline{v}}=\bar{v}, B(\bar{v}, \bar{v})=\bar{v}$, and, thus, $\left.\frac{\partial^{2} R\left(v^{*}, r\right)}{\partial v^{* 2}}\right|_{v^{*}=\bar{v}}=0$. 
Further, note that

$$
\begin{aligned}
\frac{\partial}{\partial r}\left(\left.\frac{\partial^{2} R\left(v^{*}, r\right)}{\partial v^{* 2}}\right|_{v^{*}=\bar{v}}\right)= & n F(\underline{\underline{v}})^{n-1} f^{\prime}(\bar{v})+\left(\frac{\varepsilon \lambda+\varepsilon(1-\lambda) \frac{\partial B(\bar{v}, r)}{\partial r}}{1+\varepsilon}\right) n\left(1-F(\underline{\underline{v}})^{n-1}\right) f^{\prime}(\bar{v}) \\
& +\left(\frac{\varepsilon \lambda+\varepsilon(1-\lambda) \frac{\partial B(\bar{v}, r)}{\partial r}}{1+\varepsilon}\right) n(n-1) f(\bar{v})^{2} \\
& -\frac{\partial B(\bar{v}, r)}{\partial r} n(n-1) f(\bar{v})^{2}-\frac{\partial B(\bar{v}, r)}{\partial r} n f^{\prime}(\bar{v}) \\
= & \frac{-F(\underline{\underline{v}})^{n-1} n(n-1) f(\bar{v})^{2}}{1+\varepsilon \lambda+F(\underline{\underline{v}})^{n-1} \varepsilon(1-\lambda)} \\
< & 0
\end{aligned}
$$

with the second equality following from the fact that $\frac{\partial B(\bar{v}, r)}{\partial r}=\frac{\varepsilon \lambda+F(\underline{\underline{v}})^{n-1}(1+\varepsilon-\varepsilon \lambda)}{1+\varepsilon \lambda+F(\underline{\underline{v}})^{n-1} \varepsilon(1-\lambda)}$.

Therefore, we must have $\left.\frac{\partial^{2} R\left(v^{*}, r\right)}{\partial v^{* 2}}\right|_{v^{*}=\bar{v}}>0$ for $r \in[\underline{v}, \bar{v})$ since $\left.\frac{\partial^{2} R\left(v^{*}, r\right)}{\partial v^{* 2}}\right|_{v^{*}=\bar{v}}$ is decreasing in $r$ and is zero for $r=\bar{v}$.

At $v^{*}=\bar{v}, \frac{\partial R\left(v^{*}, r\right)}{\partial v^{*}}=0$ irrespective of the seller's choice of $r$. However, because $\left.\frac{\partial^{2} R\left(v^{*}, r\right)}{\partial v^{* 2}}\right|_{v^{*}=\bar{v}}>0$ for $r \in[\underline{v}, \bar{v})$, there is some $v^{*}<\bar{v}$ that maximizes the seller's expected revenue.

Proof of Theorem 2. Recall that the following first derivative of the expected revenue function characterize the seller's expected revenue-maximizing choice of $r$ :

$$
\begin{aligned}
\frac{\partial R\left(v^{*}, r\right)}{\partial r}= & n F(\underline{\underline{v}})^{n-1}\left(F\left(v^{*}\right)-F(\underline{\underline{v}})\right) \\
& -r n F(\underline{\underline{v}})^{n-1} f(\underline{\underline{v}})\left(1+\varepsilon-\varepsilon \lambda-\varepsilon(1-\lambda) \frac{\partial B\left(v^{*}, r\right)}{\partial r}\right) \\
& +\int_{\underline{\underline{v}}}^{v^{*}}\left(\frac{\left.\varepsilon \lambda+\varepsilon(1-\lambda) \frac{\partial B\left(v^{*}, r\right)}{\partial r}\right) n(n-1) F(y)^{n-2} f(y)\left(F\left(v^{*}\right)-F(y)\right) d y}{1+\varepsilon}\right) \\
& +\frac{\partial B\left(v^{*}, r\right)}{\partial r}\left(1-F\left(v^{*}\right)^{n}\right) .
\end{aligned}
$$

Recall also that when $\rho=\lambda r+(1-\lambda) x$, the result of Mathews and Katzman (2006, Theorem 1) establishes that the seller sets $v^{*}=\bar{v}$ and sets a reserve price $r_{x}$ that satisfies the first-order condition

$$
\begin{aligned}
n F(\underline{\underline{v}})^{n-1}(1-F(\underline{\underline{v}})) & -r_{x} n F(\underline{\underline{v}})^{n-1} f(\underline{\underline{v}})(1+\varepsilon-\varepsilon \lambda) \\
& +\int_{\underline{\underline{v}}}^{\bar{v}}\left(\frac{\varepsilon \lambda}{1+\varepsilon}\right) n(n-1) F(y)^{n-2} f(y)(1-F(y)) d y=0 .
\end{aligned}
$$


We can demonstrate that $r>r_{x}$ by showing that $\left.\frac{\partial R\left(v^{*}, r\right)}{\partial r}\right|_{r=r_{x}}>0$.

Holding $\underline{\underline{v}}$ fixed,

$$
\begin{aligned}
\left.\frac{\partial R\left(v^{*}, r\right)}{\partial r}\right|_{r=r_{x}}= & n F(\underline{\underline{v}})^{n-1}\left(F\left(v^{*}\right)-F(\underline{\underline{v}})\right) \\
& -r_{x} n F(\underline{\underline{v}})^{n-1} f(\underline{\underline{v}})\left(1+\varepsilon-\varepsilon \lambda-\varepsilon(1-\lambda) \frac{\partial B\left(v^{*}, r_{x}\right)}{\partial r}\right) \\
& +\int_{\underline{\underline{v}}}^{v^{*}}\left(\frac{\varepsilon \lambda+\varepsilon(1-\lambda) \frac{\partial B\left(v^{*}, r_{x}\right)}{\partial r}}{1+\varepsilon}\right) n(n-1) F(y)^{n-2} f(y)\left(F\left(v^{*}\right)-F(y)\right) d y \\
& +\frac{\partial B\left(v^{*}, r_{x}\right)}{\partial r}\left(1-F\left(v^{*}\right)^{n}\right) .
\end{aligned}
$$

Since $B\left(v_{i}, r\right)$ is increasing in $r$ (by Lemma 1 ),

$$
\begin{aligned}
\left.\frac{\partial R\left(v^{*}, r\right)}{\partial r}\right|_{r=r_{x}}> & n F(\underline{\underline{v}})^{n-1}\left(F\left(v^{*}\right)-F(\underline{\underline{v}})\right)-r_{x} n F(\underline{\underline{v}})^{n-1} f(\underline{\underline{v}})(1+\varepsilon-\varepsilon \lambda) \\
& +\int_{\underline{\underline{v}}}^{v^{*}}\left(\frac{\varepsilon \lambda+\varepsilon(1-\lambda) \frac{\partial B\left(v^{*}, r_{x}\right)}{\partial r}}{1+\varepsilon}\right) n(n-1) F(y)^{n-2} f(y)\left(F\left(v^{*}\right)-F(y)\right) d y \\
& +\frac{\partial B\left(v^{*}, r_{x}\right)}{\partial r}\left(1-F\left(v^{*}\right)^{n}\right) .
\end{aligned}
$$

Note that

$$
\begin{aligned}
r_{x} n F(\underline{\underline{v}})^{n-1} f(\underline{\underline{v}})(1+\varepsilon-\varepsilon \lambda)= & n F(\underline{\underline{v}})^{n-1}(1-F(\underline{\underline{v}})) \\
& +\int_{\underline{\underline{v}}}^{\bar{v}}\left(\frac{\varepsilon \lambda}{1+\varepsilon}\right) n(n-1) F(y)^{n-2} f(y)(1-F(y)) d y
\end{aligned}
$$

and that (from Lemma 1)

$$
\frac{d B\left(v^{*}, r_{x}\right)}{d r}=\frac{\varepsilon \lambda+\left(\frac{n\left(1-F\left(v^{*}\right)\right) F(\underline{\underline{v}})^{n-1}(1+\varepsilon-\varepsilon \lambda)}{1-F\left(v^{*}\right)^{n}}\right)}{1+\varepsilon \lambda+\left(\frac{n\left(1-F\left(v^{*}\right)\right) F(\underline{\underline{v}})^{n-1} \varepsilon(1-\lambda)}{1-F\left(v^{*}\right)^{n}}\right)}
$$

Substituting for $r_{x} n F(\underline{\underline{v}})^{n-1} f(\underline{\underline{v}})(1+\varepsilon-\varepsilon \lambda)$ and $\frac{d B\left(v^{*}, r_{x}\right)}{d r}$ in equation (11) reveals that

$$
\begin{aligned}
& \left.\frac{\partial R\left(v^{*}, r\right)}{\partial r}\right|_{r=r_{x}}> \\
& \frac{F(\underline{\underline{v}})\{G(\underline{\underline{v}})\} \varepsilon(1-\lambda)\left\{\left(1-F\left(v^{*}\right)\right) n F(\underline{\underline{v}})^{n}(1+\varepsilon(1-\lambda))+\left(1-F\left(v^{*}\right)^{n}\right) F(\underline{\underline{v}}) \varepsilon \lambda\right\}}{(1+\varepsilon) F(\underline{\underline{v}})\left\{\left(1-F\left(v^{*}\right)\right) n F(\underline{\underline{v}})^{n} \varepsilon(1-\lambda)+\left(1-F\left(v^{*}\right)^{n}\right) F(\underline{\underline{v}})(1+\varepsilon \lambda)\right\}},
\end{aligned}
$$


where $G(\underline{\underline{v}}) \equiv 1-n F(\underline{\underline{v}})^{n-1}+(n-1) F(\underline{\underline{v}})^{n}$. Because $1-n F(\underline{\underline{v}})^{n-1}+(n-1) F(\underline{\underline{v}})^{n}>0$ as long as $F(\underline{\underline{v}})<1,\left.\frac{\partial R\left(v^{*}, r\right)}{\partial r}\right|_{r=r_{x}}>0$, and thus $r>r_{x}$. 


\section{References}

Anderson, S., Friedman, D., Milam, G., \& Singh, N. (2007a). Buy It Now: A Hybrid Internet Market Institution. Working Paper, University of California, Santa Cruz.

Anderson, S., Friedman, D., Milam, G., \& Singh, N. (2007b). Seller Strategies on eBay...Does Size Matter?. Working Paper, University of California, Santa Cruz.

Ariely, D., \& Simonson, I. (2003). Buying, Bidding, Playing, or Competing? Value Assessment and Decision Dynamics in Online Auctions. Journal of Consumer Psychology, 13(1-2), 113-123.

Bernard, J. C. (2005). Evidence of Affiliation of Values in a Repeated Trial Auction Experiment. Applied Economics Letters, 12(11), 687-691.

Bose, S., \& Daripa, A. (2006). Optimal Sale: Auctions with a Buy-Now Option. Working Paper BWPEF 0702, Birkbeck, University of London.

Budish, E. B., \& Takeyama, L. N. (2001). Buy Prices in Online Auctions: Irrationality on the Internet?. Economics Letters, $72(3), 325-333$.

Corrigan, J. R., \& Rousu, M. C. (2006). Posted Prices and Bid Affiliation: Evidence from Experimental Auctions. American Journal of Agricultural Economics, 88(4), 10781090.

Dholakia, U. M., \& Simonson, I. (2005). The Effect of Explicit Reference Points on Consumer Choice and Online Bidding Behavior. Marketing Science, 24 (2), 206-217.

Dodonova, A., \& Khoroshilov, Y. (2004). Anchoring and Transaction Utility: Evidence from On-line Auctions. Applied Economics Letters, 11(5), 307-310.

Drichoutis, A. C., Lazaridis, P., \& Nayga, Jr., R. M. (2007). The Role of Reference Pirces in Experimental Auctions. Economics Letters, forthcoming.

Durham, Y., Roelofs, M. R., \& Standifird, S. S. (2004). eBay's Buy-It-Now Function: Who, When, and How. Topics in Economic Analysis 8 Policy, 4(1), Article 28. Available online at: http://www.bepress.com/bejeap/topics/vol4/iss1/art28.

Grebe, T., Ivanova-Stenzel, R., \& Kröger, S. (2006). How eBay Sellers Set "Buy-It-Now" Prices - Bringing the Field into the Lab. Governance and the Efficiency of Economic Systems Working Paper Number 181, University of Mannheim. 
Häubl, G., \& Popkowski Leszczyc, P. T. L. (2003). Minimum Prices and Product Valuations in Auctions. Working Paper 03-117, Marketing Science Institute.

Hidvégi, Z., Wang, W., \& Whinston, A. B. (2006). Buy-Price English Auction. Journal of Economic Theory, 129(1), 31-56.

Hof, R. D. (2001). The People's Company. BusinessWeek Online, December 3.

Ivanova-Stenzel, R., \& Kröger, S. (2007). Price Formation in a Sequential Selling Mechanism. Journal of Economic Behavior $\&$ Organization, forthcoming.

Kahneman, D., \& Tversky, A. (1979). Prospect Theory: An Analysis of Decision under Risk. Econometrica, 47(2), 263-292.

Kalyanaram, G., \& Winer, R. S. (1995). Empirical Generalizations from Reference Price Research. Marketing Science, 14(3), G161-G169.

Kamins, M. A., Drèze, X., \& Folkes, V. S. (2004). Effects of Seller-Supplied Prices on Buyers' Product Evaluations: Reference Prices in an Internet Auction Context. Journal of Consumer Research, 30(4), 622-628.

Kane, M. (2002). "Buy It Now" Clicks with eBay Sellers. CNET News, August 8.

Kirkegaard, R., \& Overgaard, P. B. (2007). Buy-Out Prices in Auctions: Seller Competition and Multi-Unit Demands. Working Paper, Brock University.

Köszegi, B., \& Rabin, M. (2006). A Model of Reference-Dependent Preferences. Quarterly Journal of Economics, 121(4), 1133-1165.

List, J. A., \& Shogren, J. F. (1999). Price Information and Bidding Behavior in Repeated Second-Price Auctions. American Journal of Agricultural Economics, 81(4), 942-949.

Mathews, T. (2002). Buyout Options in Internet Auction Markets. Unpublished PhD Dissertation, State University of New York at Stony Brook.

Mathews, T. (2003). A Risk Averse Seller in a Continuous Time Auction with a Buyout Option. Brazilian Electronic Journal of Economics, 5(2).

Mathews, T. (2004). The Impact of Discounting on an Auction with a Buyout Option: a Theoretical Analysis Motivated by eBay's Buy-It-Now Feature. Journal of Economics (Zeitschrift für Nationalökonomie), 81(1), 25-52. 
Mathews, T., \& Katzman, B. (2006). The Role of Varying Risk Attitudes in an Auction with a Buyout Option. Economic Theory, 27(3), 597-613.

Mazumdar, T., Raj, S. P., \& Sinha, I. (2005). Reference Price Research: Review and Propositions. Journal of Marketing, 69(4), 84-102.

Milgrom, P. (1989). Auctions and Bidding: A Primer. Journal of Economic Perspectives, 3(3), 3-22.

Myerson, R. B. (1981). Optimal Auction Design. Mathematics of Operations Research, 6(1), $58-73$.

Nunes, J. C., \& Boatwright, P. (2004). Incidental Prices and Their Effect on Willingness to Pay. Journal of Marketing Research, 41(4), 457-466.

Popkowski Leszczyc, P. T. L., Qiu, C., \& He, Y. (2007). Empirical Testing of the Reference Price Effect of Buy-now Prices in Internet Auctions. Working Paper, University of Alberta.

Reynolds, S. S., \& Wooders, J. (2007). Auctions with a Buy Price. Economic Theory, forthcoming.

Riley, J. G., \& Samuelson, W. F. (1981). Optimal Auctions. American Economic Review, $71(3), 381-392$.

Rosenkrantz, S., \& Schmitz, P. W. (2007). Reserve Prices in Auctions as Reference Points. Economic Journal, 117(520), 637-653.

Seifert, S. (2006). Posted Price Offers in Internet Auction Markets. Springer-Verlag, Berlin.

Shahriar, Q., \& Wooders, J. (2006). An Experimental Study of Auctions with a Buy Price Under Private and Common Values. Working Paper, University of Arizona.

Suter, T. A., \& Hardesty, D. M. (2005). Maximizing Earnings and Price Fairness Perceptions in Online Consumer-to-Consumer Auctions. Journal of Retailing, 81(4), 307-317.

Tversky, A., \& Kahneman, D. (1991). Loss Aversion in Riskless Choice: A ReferenceDependent Model. Quarterly Journal of Economics, 106(4), 1039-1061.

Vickrey, W. (1961). Counterspeculation, Auctions, and Competitive Sealed Tenders. Journal of Finance, 16(1), 8-37. 
Wang, R. (1993). Auctions versus Posted-Price Selling. American Economic Review, 83(4), 838-851.

Wang, X., Montgomery, A. L., \& Srinivasan, K. (2004). When Auction Meets Fixed Price: A Theoretical and Empirical Examination of Buy-It-Now Auctions. Working Paper, Carnegie Mellon University. 